\title{
Impact of the Prolymphangiogenic Crosstalk in the Tumor Microenvironment on Lymphatic Cancer Metastasis
}

\author{
Simona L. Schlereth, ${ }^{1}$ Nasrin Refaian, ${ }^{1}$ Sandra Iden, ${ }^{2}$ \\ Claus Cursiefen, ${ }^{1}$ and Ludwig M. Heindl ${ }^{1}$ \\ ${ }^{1}$ Department of Ophthalmology, University of Cologne, Kerpener Straße 62, 50937 Cologne, Germany \\ ${ }^{2}$ Cologne Excellence Cluster on Cellular Stress Responses in Aging-Associated Diseases (CECAD) and Center for \\ Molecular Medicine Cologne (CMMC), University of Cologne, Joseph-Stelzmann-Straße 26, 50931 Cologne, Germany \\ Correspondence should be addressed to Simona L.Schlereth; simona.schlereth@uk-koeln.de
}

Received 11 April 2014; Accepted 14 August 2014; Published 1 September 2014

Academic Editor: Zhen Chen

Copyright (C) 2014 Simona L. Schlereth et al. This is an open access article distributed under the Creative Commons Attribution License, which permits unrestricted use, distribution, and reproduction in any medium, provided the original work is properly cited.

Lymphangiogenesis is a very early step in lymphatic metastasis. It is regulated and promoted not only by the tumor cells themselves, but also by cells of the tumor microenvironment, including cancer associated fibroblasts, mesenchymal stem cells, dendritic cells, or macrophages. Even the extracellular matrix as well as cytokines and growth factors are involved in the process of lymphangiogenesis and metastasis. The cellular and noncellular components influence each other and can be influenced by the tumor cells. The knowledge about mechanisms behind lymphangiogenesis in the tumor microenvironmental crosstalk is growing and offers starting points for new therapeutic approaches.

\section{Introduction}

The spread of tumor cells via the lymphogen route into the draining lymph nodes is common in many malignant tumors, including malignant melanoma of the skin [1], head and neck squamous cell carcinoma [2], squamous cell carcinoma of the uterine cervix [3], colorectal carcinoma [4], breast cancer [5], and malignant melanoma of the conjunctiva [6-13]. Sentinel lymph node biopsy allows early detection of micrometastasis resulting in staging and treatment changes.

The outgrowth of new lymphatic vessels from preexisting lymphatic vessels (lymphangiogenesis) has recently gained much interest in tumor research since it is the initial step in lymphogenic metastasis [14]. Although the role of intratumoral versus peritumoral lymphangiogenesis is still debated, its role as a decisive risk factor for tumor metastasis is now established.
Lymphangiogenesis is mediated by binding of the lymphangiogenic growth factors vascular endothelial growth factor- (VEGF-) C and VEGF-D to their specific lymphatic receptor, VEGF receptor 3 [15]. VEGF-C and VEGF-D can be released by a variety of tumor cells or by peritumoral nonmalignant cells of the tumor microenvironment [1619], thus explaining the occurrence of tumor-associated lymphangiogenesis.

The cellular crosstalk in the tumor microenvironment is likely to play a role in promoting lymphangiogenesis and thus lymphatic metastasis. A variety of factors in the tumor microenvironment, including extracellular matrix (ECM) with cancer-associated fibroblasts (CAFs) and mesenchymal stem cells (MSCs), cells of the innate and adaptive immune system (dendritic cells, macrophages, and T- and B-cells) as well as cytokines and growth factors produced by the tumor and stromal cells [20,21], has been considered to contribute to this process. 
This review focuses on the role of tumor microenvironmental components in tumor-associated lymphangiogenesis and therefore the lymphatic metastasis cascade. Better understanding of these mechanisms is required to improve future therapeutic strategies aiming at minimizing the lymphatic spread of the tumor to the regional lymph nodes in order to the prolong survival of cancer patients.

\section{Cytokines and Growth Factors Control Lymphangiogenesis}

Growth factors of the vascular endothelial growth factor (VEGF) family are well understood in lymphangiogenesis. VEGF is the target of one of the first therapeutics: VEGF blocking antibody bevacizumab is used in colon cancer [22].

VEGF-D has been shown to induce the formation of blood and lymphatic vessels in tumors and VEGF-D expression on tumor cells led to increased lymphatic metastasis [23]. However, other authors emphasize the tissue specific effects on blood or lymph endothelial growth of VEGF-D [24]. In many forms of human cancer, a correlation of VEGF$\mathrm{C}$ expression within the primary tumor and lymph node metastasis has been observed [25-30]. VEGF-C overexpression in breast cancer increased intratumoral lymphangiogenesis and was associated with enhanced metastasis into draining lymph nodes and lungs [31]. This might be caused by a tumor secreted VEGF-C dependent increase of matrix metalloproteinase- (MMP-) 9 production, followed by an increased matrix degradation and migration [32]. Other studies conclude that tumor derived VEGF-C draining to the regional lymph nodes may promote the outgrowth of lymph node metastasis [33].

Controversy exists whether VEGF-A is able to induce lymphangiogenesis. Recent studies indicate that the VEGFA/VEGF-R2 signaling pathway is involved in lymphangiogenesis [14, 34]. Hirakawa et al. detected that VEGF-A overexpressing primary tumors can induce lymph node lymphangiogenesis and were associated with increased lymph node metastasis [35]. Lymph node lymphangiogenesis per se is thought to actively promote metastasis [36] and can also be induced by tumor cells [37].

Beside the VEGF family, the angiopoietins- (Ang-) 1 and Ang-2 are important in tumor angiogenesis. They bind to their receptors Tie 1 and Tie 2 on vascular endothelial cells and are involved in lymphangiogenesis and metastasis [38-42]. Ang-2 is upregulated by different factors including VEGF-A or insulin like growth factor 1 and induces angiogenesis in the presence of VEGF-A [39]. A reduced prognosis has been shown for different tumors overexpressing Ang2 [39]. Ang-2 seems to have a destabilizing effect on blood vessels, an early step in neovascularization [43], whereas Ang1 expressed by pericytes and others promotes stability of vessels [38]. In pancreatic cancer, elevated circulating Ang2 was correlated with the extent of lymphatic metastasis and therefore seems to participate in the control of lymphatic metastasis [44].

Other factors that are involved in lymphangiogenesis are platelet derived growth factor- (PDGF-) BB [45], fibroblast growth factor- (FGF-) 2 [46], sphingosine 1 phosphate (S1P) [47], and hepatocyte growth factor (HGF) [48].

Lymphatic endothelium cells express different markers, including lymphatic vessel endothelial hyaluronan receptor1 (LYVE-1), podoplanin D2-40, prospero homeobox transcription factor 1 (prox1), and VEGF-R3 [49]. Lately, besides the significant correlation of lymphatic markers LYVE-1 and podoplanin D2-40 [50] in many forms of cancer and their negative correlation to prognosis mentioned above, proxl and forkhead box (FOX) C2, regulators of angiogenesis and lymphangiogenesis, came into focus of cancer research. Sasahira et al. report that proxl expression correlated with progression, lymphatic vessel density, metastasis, and worse prognosis [51]. Proxl activated VEGF-C expression in vitro, whereas FOXC2 enhances proxl and VEGF-A expression [51].

Chemokines are important signal proteins, involved in cell migration and chemotaxis. Chemokine ligands bind to their specific receptors. Metastatic cells seem to adopt this mechanism and express analogue receptors to improve their migration to distinct tissues [52]. Many different chemokine pathways are known and their role in cancer has been completely and well reviewed by others [53]; therefore, in this review we focus on chemokine axes involved in lymphatic metastasis: the chemokine receptor 7 (CCR7) with its ligands CCL19 and 21 and the CXCR4/CXCR12 axis. The CCR7 axis is a very important physiological axis for migration of immune cells and CCL21 regulates the homing to the lymphoid tissues [54].

Chemokines have been shown to be involved in tumor lymphangiogenesis and metastasis; for example, VEGF-C upregulated chemokine ligand 21 (CCL21) on lymphatic endothelium, whereby CCR7 expressing tumor cells were attracted towards the lymphatic vessels [32].

Many studies show that primary tumor cells and metastatic cells express CCR7 in the draining lymph node and that there is a significant correlation between lymph node metastasis and CCR7 expression in many tumor entities [5558]. In one study the authors suggest that CCR7 enhances metastasis by upregulating MMP-9 expression [59]. Li et al. showed that hypoxia may induce CCR7 expression on tumor cells to stimulate migration and invasion of lung cancer cells, using the HIF $1 \alpha$ and HIF $2 \alpha$ pathway [60].

Other chemokines such as CXC chemokine type 2 (CXCR2) seem to be involved in lymphangiogenesis, as a high expression of CXCR2 is associated with increased lymph node metastases and a reduced prognosis in resected esophageal carcinoma [61].

Chemokine receptor CXCR4 is involved in metastasis of multiple cancer entities, including breast cancer [62], gastric cancer [63], prostate cancer [64], melanoma [65], uveal melanoma [66], or glioblastoma [67], to name just a few.

CXCR4 is upregulated in metastatic breast cancer cell lines and lymph node metastasis [62], and cells expressing CXCR4 predominantly migrate to tissues that express the ligand CXCL12 [62]. These tissues include the common sides of breast cancer metastasis, including lung, lymph node, brain, and bone marrow $[5,62]$. Interestingly, in vivo inhibition of the CXCR4/CXCL12 axis reduced lymph node and lung metastasis [62]. Others showed that the de novo 


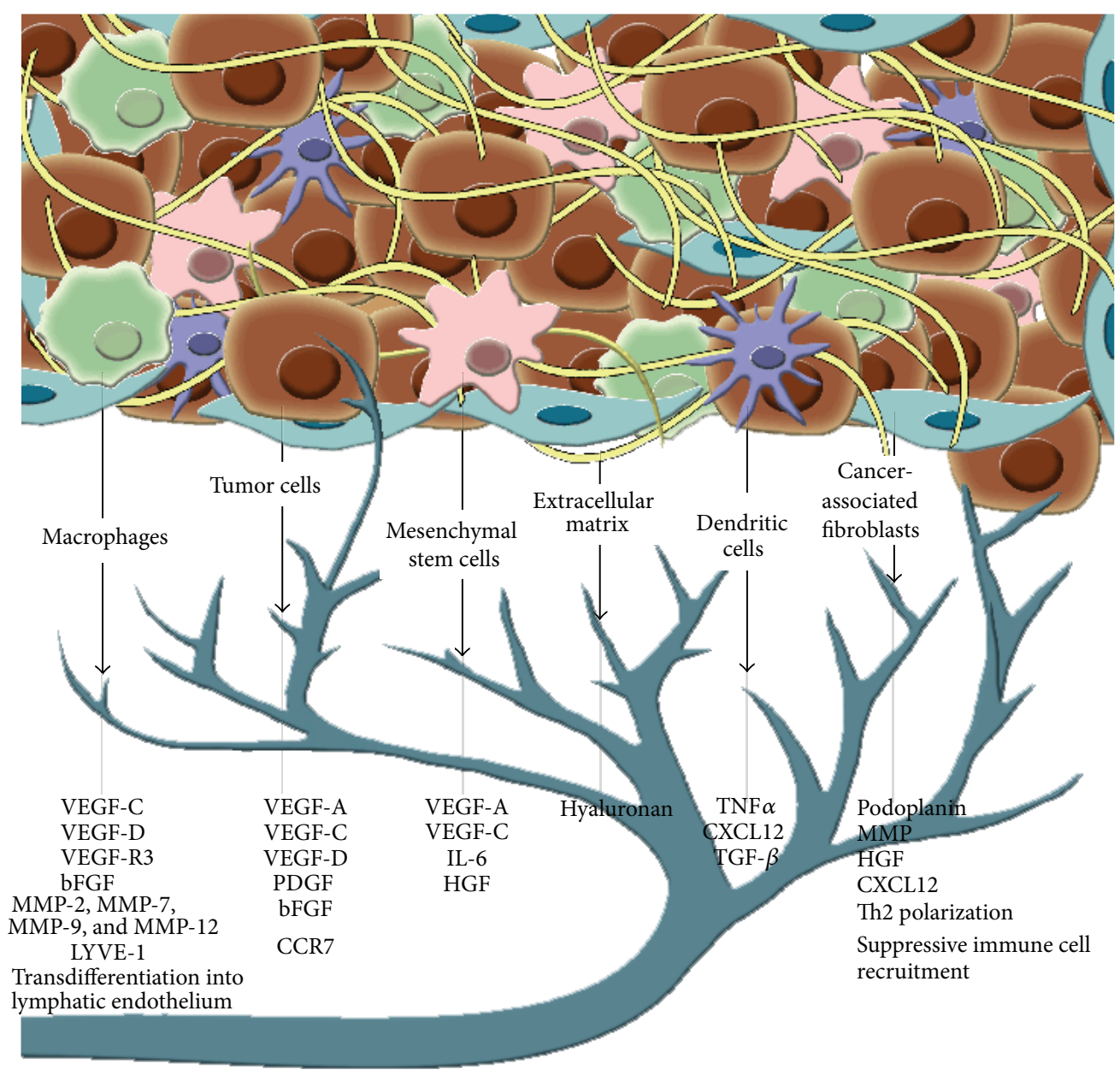

FIGURE 1: The prolymphangiogenic crosstalk of the tumor microenvironment: tumor cells as well as macrophages, dendritic cells, the extracellular matrix, cancer-associated fibroblasts, and mesenchymal stem cells can promote lymphangiogenesis by secretion or expression of different factors.

expression of CXCR4 is sufficient for metastasis to occur, shown by the B16 melanoma cell line transfected with CXCR4 [68]. In gastric cancer, CXCR4 expression is involved in lymph node metastasis $[63,69]$.

In prostate cancer, CXCR4 expression has been shown to increase tumor invasion and metastasis [64]. It may therefore serve as a prognostic marker in prostate cancer [70].

One last example is the CXCR3-CXCL9 axis: CXCR3 expression has been detected in several human melanoma cell lines and the mouse melanoma cell line B16F10. The loss of CXCR3 expression reduces lymph node metastasis in a murine melanoma model [71].

To summarize, the best-studied group of growth factors is the VEGF family, whereby in many forms of cancer an association between VEGF-C and metastasis has been recognized. Within the chemokines in cancer, the CXCR4/CXCL12 axis is currently best characterized and CXCR4 is a ubiquitously expressed receptor on tumor cells. Chemokine expression is often associated with elevated lymphatic metastasis. Tumor cells seem to have adopted these migration paths for facilitated access into lymphatic vessels and towards the draining lymph nodes. Cytokines and growth factors involved in lymphangiogenesis are summarized in Figure 1 and explained in detail in the following sections.

\section{Senescence and Senescence-Associated Secretory Phenotype: Cell Autonomous and Nonautonomous Roles}

Most mammalian cells have a limited proliferative capacity, and after various rounds of proliferation accompanied by telomere shortening, cells undergo permanent cell cycle arrest and enter a state called cellular senescence. Senescent cells remain viable and metabolic active and thereby further contribute to tissue homeostasis. Senescence can be prematurely induced by stress factors and DNA damage, for example, upon oncogene expression or UV irradiation, and is mediated by activation of the Arf/p53/p21 and/or p16/pRb pathways [72]. Senescence has been observed in various cell types of the tumor microenvironment including fibroblasts and immune cells and is considered a physiological tumorsuppressive mechanism in human cancers as it counteracts proliferation of premalignant cells $[73,74]$. Human nevi, for 
instance, are frequently positive for activating BRafV600E mutations; however, these cells bear a senescent phenotype [75]. Abrogation of such oncogene-induced senescence by PI3K activation allows for melanoma formation [76]. Induction of cellular senescence therefore has been recognized as promising therapeutic approach to prevent the proliferation of cancer cells. Recently, however, it became apparent that senescence in surrounding tissue cells might have both tumor-suppressive as well as promoting consequences [77]. Senescent cells secrete a variety of growth and regeneration promoting cytokines, chemokines, growth factors, and proteases, a phenomenon called senescence-associated secretory phenotype (SASP). SASP has recently been described for a variety of cancers and is considered to significantly modulate the properties of the specific tumor microenvironment. SASP factors can induce recruitment of immune cells like NKcells and T-cells that help eliminate premalignant cells, and such NK-cell recruitment appears to be critical for tumor regression in vivo [78]. On the contrary, senescent tissue cells via SASP factors can directly promote tumor cell proliferation, invasion, and immune-editing to escape elimination by the immune system, thus overall providing a tumor-permissive micromilieu. Importantly, induction of senescence in NK cells has recently been reported to promote vascular remodeling and angiogenesis [79], opening the possibility that senescence and SASP may also contribute to tumor-associated lymphangiogenesis, although this remains to be demonstrated experimentally.

In the case of SASP of senescent fibroblasts in the tumor microenvironment, a significant overlap of its expression profile with that of cancer-associated fibroblasts (CAFs, see below) has been reported. For instance, upregulation of IL6, IL-8, various CXCLs, and MMP-3 constitutes a common signature of CAFs and SASP [80]. Together, though induction of permanent cell cycle arrest within tumor cells is a desirable feature to suppress tumorigenesis, senescence of immune and surrounding tissue cells may have opposing outcome on tumor progression and angiogenesis, underscoring the importance of a better understanding of the cross-talk between tumor cells and their particular microenvironment.

\section{Extracellular Matrix (ECM) with Cancer-Associated Fibroblasts (CAFs) and Mesenchymal Stem Cells (MSCs) Promote Lymphangiogenesis}

Tumor-associated lymphangiogenesis may arise in the tumor microenvironment. The tumor microenvironment is mainly composed of the extracellular matrix (ECM) enriched with nonmalignant stroma cells, such as cancer-associated fibroblasts (CAFs) and mesenchymal stem cells (MSCs).

4.1. Extracellular Matrix (ECM). The ECM is a complex three-dimensional network made of fibrous proteins, such as collagen and fibronectin, and nonfibrous proteins, namely, glycosaminoglycans, proteoglycans, and glycoproteins. Located between cell clusters in all tissues, it strengthens the tissues, provides a channel for communication and migration within the tissue and under physiologic conditions, and acts as scaffold to keep growth factors insoluble [8183]. Cancer cells may stimulate the tumor microenvironment by producing growth factors, including PDGF, transforming growth factor- (TGF-) $\beta$, VEGF, basic fibroblast growth factor (bFGF), and interleukins [83]. The altered expression of such mediators by tumor cells, which also have autocrine effects, often leads to production of proteolytic enzymes by the tumor cells $[84,85]$. They may also stimulate stromal cells, for example, fibroblasts, to secrete molecules with a similar proteolytic effect on the ECM [86].

Therefore, not only tumor cells, but also stroma cell activation may modify the ECM towards an environment that promotes microinvasion of tumor cells [87]. Major components digesting ECM and cell surface proteins include MMPs, bone morphogenic protein 1 (BMP1), tissue serine proteinases, and adamalysin-related membrane proteinases [88]. Remodeling the ECM can significantly modulate migratory and angiogenic properties, for instance by release of cryptic protein sites and specific new molecule fragments [81]. Cryptic protein domains in ECM components such as fibronectin are typically masked in a folded structure and are thereby not accessible. Proteolytic enzymes can release these domains and open new integrin binding sites and antiangiogenic sequences [81] or activate latent TGF- $\beta$ by proteolytic cleavage [89].

Hyaluronan, an important mucopolysaccharide of the ECM, provides an environment of proliferation and migration [90]. Interestingly, lymphatic endothelial cells exclusively express a hyaluronan receptor, known as LYVE-1 [91]. The functional impact of LYVE-1 receptors on tumor-associated lymphangiogenesis is not fully understood. However, it was demonstrated recently that low molecular weight hyaluronan promoted lymphatic endothelial cell (LEC) proliferation, migration, and tube formation, mediated via binding to LYVE-1 [92]. Therefore, in the tumor context hyaluronan seems to promote hem- and lymphangiogenesis.

In summary, dynamic remodeling of the ECM and cell-substrate interactions display one important feature in tumor-mediated lymphangiogenesis.

4.2. Cancer-Associated Fibroblasts (CAFs). Recently, there is increasing evidence that fibroblasts are a prominent modifier of cancer progression $[93,94]$. CAFs are tall spindle shaped mesenchymal cells that share characteristics with smooth muscle cells and fibroblasts [83]. They can immunohistochemically be identified with a combination of different markers, since they show an elevated expression of $\alpha$-smooth muscle actin, vimentin, desmin, and fibroblast-activating protein (FAP) compared to normal stromal fibroblasts [95, 96]. CAFs can promote tumor growth and progression but also influence the stromal microenvironment by producing large amounts of growth factors, cytokines and extracellular matrix proteins (e.g., collagen and fibronectin), and MMPs $[21,97,98]$. Bauer et al. showed an increased expression of TGF- $\beta 2$, insulin-like growth factor-binding protein 2, tumor necrosis factor (ligand) superfamily member 4 , and heparin-binding EGF-like growth factor in CAFs compared 
to regular fibroblasts [99]. Moreover, CAFs secrete growth factors such as HGF or TGF- $\beta$ but also ECM glycoproteins such as Tenascin-C (TNC) [100]. Tumor cells on the other hand secrete TGF- $\beta$ or platelet-derived growth factor (PDGF), which are important factors for interactions between tumor cells and fibroblasts. TGF- $\beta$ modulates fibroblasts and myofibroblasts towards CAFs [101, 102]. CAFs support tumor growth and metastasis indirectly through recruitment of immune cells such as tumor-associated macrophages (TAMs), myeloid suppressor cells (MDSCs), or regulatory T-cells $\left(\mathrm{T}_{\text {regs }}\right)$. All these cells are influencing the tumor microenvironment towards an immune suppressive environment and are thereby protecting the tumor. In vivo experiments showed that elimination of CAFs favors a Th1 over a Th2 polarization in the tumor microenvironment of a murine breast cancer model [103].

The modulation of the tumor microenvironment induces angiogenesis and lymphangiogenesis. CAFs secrete the stromal cell-derived factor 1 (SDF1), also known as CX chemokine ligand 12 (CXCL12), which is important in recruitment of endothelial progenitor cells (EPCs) in tumors. CXCL12 itself stimulates the tumor growth directly, via the CXC-chemokine receptor 4 (CXCR4), expressed among others on human breast carcinoma cells [104]. An elevated amount of CAFs significantly correlated with an increased lymphatic vessel density in ovarian cancer [105]. Another study showed that CAFs express podoplanin in the context of different tumors. The podoplanin expression of CAFs positively correlated with the VEGF-C expression of the tumor cell and the intratumoral amount of CD31+ blood vessels. In contrast, the increased expression of podoplanin in CAFs negatively correlated with peritumoral microvessels and LYVE-1 positive lymphatic vessels. The expression of podoplanin in CAFs did not correlate with the VEGF-A or VEGF-D expression in tumor cells [106].

Summarizing, CAFs seem to be important in the tumor microenvironment, where they indirectly contribute to lymphangiogenesis and metastasis by the induction of Th2 Tcells, recruitment of suppressive immune cells, and secretion of growth factors. However, the exact mechanisms are not fully understood.

4.3. Mesenchymal Stem Cells (MSCs). MSCs are nonhematopoietic multipotent cells that are able to differentiate into bone, fat, or cartilage tissue. They are involved in tissue repair and maintenance and have a tropism to wounded tissue [107]. In the context of trauma or tumor, they are capable of migrating towards these tissue sides, induced by chemokines or inflammatory factors [108]. MSCs show a specific migration to growth factors such as PDGF, EGF, and VEGF and a reduced migration in the presence of specific inhibitors, such as Glivec, Erbitux, and Avastin [109]. (More to therapeutic approaches is listed below; see point 5.) MSC themselves produce an amount of tumor promoting factors, including IL-6 [86], TGF- $\beta$, VEGF, and HGF $[107,110]$.

Using these factors, MSCs are capable of enhancing lymphangiogenesis and lymphatic metastasis. LECs express an HGF receptor (also known as c-Met or MET) and HGF promotes lymphatic vessel function and formation [111]. In vitro cocultures of MSCs and endothelial progenitor cells (EPCs) revealed that MSCs secreted VEGF-A in bioavailable amounts $(350 \mathrm{pg} / \mathrm{mL})$, despite the secretion of VEGF inhibitors (sVEGF-R1/sVEGF-R2) by EPCs [110]. Moreover, in a syngeneic mouse model, subcutaneous coinjection of MSCs and EPCs in Matrigel induced both blood- and lymphangiogenesis [110], highlighting the proangiogenic effect of MSCs in vivo.

VEGF-A can induce proliferation and migration of lymphatic endothelial cells (LECs). Dellinger and Brekken showed that VEGF-R2 acts as the primary receptor controlling VEGF-A induced lymphangiogenesis in an ERK1/2 and Akt-dependent manner [112]. In inflammatory neovascularization, VEGF-A stimulates LECs and lymphangiogenesis indirectly via macrophage recruitment [18].

As mentioned above, MSCs are capable of secreting IL6. IL-6 and a proinflammatory cytokine is upregulated in different cancer entities. For example, a significant correlation between IL-6 protein and VEGF-C mRNA with lymph node metastasis in human oral squamous cell carcinoma has been demonstrated [113]. Moreover, in vitro experiments revealed that IL-6 induces VEGF-C expression in human oral squamous cell carcinoma cell line [113] and VEGF-C expression in IL-6 treated murine LECs [114].

MSCs are able to express a lymphatic phenotype, when cultured in lymphatic induced medium and VEGF-C [115]. Vice versa, tumor cells secrete growth factors, cytokines, and chemokines to promote the migration and survival of MSCs [108]. Karnoub et al. reported that MSC infiltration into tumor stroma promotes metastasis in breast cancer [116].

In conclusion, MSCs seem to have direct and indirect effect on lymphangiogenesis and lymphatic metastasis, mainly via VEGF-A, VEGF-C, HGF, and IL-6.

\section{Immune Cells (Dendritic Cells, Macrophages) Control Lymphangiogenesis}

Tumor-associated lymphangiogenesis is under the influence of innate immune cells of the tumor microenvironment, especially dendritic cells and macrophages.

5.1. Dendritic Cells (DCs). DCs are the most potent antigen presenting cells of the human body. They can be subdivided into different subsets and to fully understand their functions in the tumor microenvironment, DC subsets should be examined individually with regard to influences on their behavior, dependent on different local factors. DCs are involved in tumor immunology and angiogenesis by stimulating inflammation or inducting tolerance. They can internalize tumor antigen and cross-present it to T-cells within the draining lymph node. This is an important step towards an antitumoral immune reaction [117]. However, controversial data exists on their role in the tumor microenvironment, DC activation, or tolerance induction. On the one hand, DNA derived from necrotized tumor cells may be involved in the DC activation [118]. On the other hand, tumor cells have been shown to inhibit DC maturation through the secretion of IL-10 [119]. 
Within DCs, two major subsets can be differentiated: the myeloid DCs (mDCs, also known as conventional DCs) and the plasmacytoid DCs (pDCs) [120]. Both can be induced towards a tumor promoting state in the tumor microenvironment: $\mathrm{mDC}$ contribute to the survival of multiple melanoma cells [121]. pDCs seem to have immunoregulatory properties in the tumor microenvironment and induce $\mathrm{T}_{\text {regs }}$ in the human ovarian carcinoma [122]. pDCs also contribute to angiogenesis by producing proangiogenic cytokines, such as IL-8 and tumor necrosis factor alpha (TNF $\alpha$ ) in the ovarian carcinoma [123]. pDCs were detected in solid tumor tissue and metastatic cervical lymph nodes in head and neck squamous cell carcinoma [124]. In breast cancer, pDCs infiltration into the primary tumor was associated with shorter overall survival [125].

In general, tumor-associated DCs (TADCs) can secrete different proangiogenic factors, such as TGF- $\beta$, granulocyte macrophage colony-stimulating factor (GM-CSF), CXCL12, or TNF $\alpha[126,127]$. TADCs are able to differentiate into endothelial-like cells under tumor specific culture conditions [128] and CD34-CD11c+ immature DCs cocultured with tumor-cell conditioned media showed an endothelial-like differentiation [129]. Whether or not DCs participate in lymphangiogenesis is still a topic of ongoing research.

DCs can be influenced by VEGFs. VEGF has been shown to inhibit DC maturation by blocking NF- $\kappa \mathrm{B}$ transcription [130]. In the cornea, VEGF-R3 blocking antibody reduced the DC migration towards the draining lymph nodes [131].

DCs as antigen presenting cells are able to take up antigen and migrate to the draining lymph node, guided through a CCL21 gradient. Interestingly, some tumor cells express the CCL21 receptor CCR7, thereby enabling them to access lymphatic vessels $[62,64,132]$.

Regarding surface receptors of dendritic cells, programmed cell death ligand 1, PD-L1, came into focus of interest (see therapeutic approaches below). Also known as B7 homolog 1 , this transmembrane protein seems to play a major role in suppressing the immune system. PD-1 and its ligand function as a complex transmit an inhibitory signal which downregulates T-cell activation and proliferation. The ligand PD-L1 is expressed on antigen presenting cells, whereas the receptor PD-1 has been found on activated Tor B-cells, macrophages, and myeloid cells as well as multiple tumor cells [133-136] and in vitro cell lines of uveal melanoma and cutaneous melanoma [137].

In breast cancer, sentinel lymph nodes with metastasis were associated with fewer mature dendritic cells within the lymph node [138]. Similarly, immature DCs have been detected in melanoma metastasis [139], but also the presence of mature DCs within the tumor tissue correlated with lymph node metastasis [125]. High mobility group box 1 (HMGB1) secreted by tumor cells induced the suppression of DCs and is associated with lymph node metastasis in human colon cancer [140]. Similarly, lymph node metastasis significantly correlated with number of DC expression in gastric cancer [141].

Recently a distinct population of DCs, namely the 6-sulfo $\mathrm{LacNAc}(+)$ DCs (slanDCs) were detected in metastatic tumor draining lymph nodes. Here, slanDCs surrounded the cancer cells, while being absent at the primary tumor side [142].

Taken together, DCs are able to secrete proangiogenic factors and induce an immune tolerant milieu in the tumor microenvironment. VEGF secreted by tumor cells or tumorassociated macrophages inhibits DC maturation, and a reduced number of mature dendritic cells can be associated with elevated lymph node metastasis in breast cancer [138]. However, due to their various subgroups, further studies are needed to fully understand their impact on lymphangiogenesis and metastasis.

5.2. Macrophages. Macrophages play an essential role in driving tumor hem- and lymphangiogenesis [143]. Known as tumor-associated macrophages (TAMs), they may sense hypoxia in tumor tissue and secrete VEGFs, basic fibroblast growth factor (bFGF), thymidine phosphorylase (TP), MMP2, MPP-7, MPP-9 and MPP-12 [144], and urokinase type plasminogen activator (uPA) [145] to induce both hem- and lymphangiogenesis. TAMs do not only express prolymphangiogenic factors VEGF-C, VEGF-D, and VEGF-R3 [17], but they can also transdifferentiate into lymphatic endothelium [146]. TAMs have also been shown to express LYVE-1 $[147,148]$ and F4/80+ LYVE-1 + macrophages integrated into peritumoral lymphatic vessels [148]. TAMs are often regulated towards an M2 phenotype. In uveal melanoma, these M2 macrophages were found to be mainly CD68+ CD163+ and high amounts of these cells were associated with a poorer prognosis [149]. This observation has also been made in a variety of other tumor entities, for example, breast cancer [150], glioma [151], or melanoma [152]. In cutaneous squamous cell carcinoma, elevated VEGF-C levels derived from TAMs were associated with increased peritumoral lymphatic vessel density [153] and may thereby coordinate metastasis [154]. Depleting macrophages during tumor induction reduced incidence of ocular tumors and improved survival in mice $[149,155,156]$. VEGF-A and VEGF-C as well as MMP-9, secreted by TAMs and tumor cells, have been shown to induce peritumoral lymphangiogenesis $[17,157]$. VEGF-A hereby may stimulate the upregulation of VEGF-C expression or through binding on VEGF-R2 expressed on lymphatic endothelium [42].

Other proangiogenic effects of TAMs can also be achieved indirectly, for example, via inhibition of DC maturation, and thereby contributing to an immune tolerant status [158]. An increased amount of immature DCs within tumor tissue was associated with elevated tumor vascularization [158]. This inhibitory and immune-suppressive effect is mainly achieved by interleukin 10, prostaglandin E2 (PGE2), and TGF- $\beta$ secretion of TAMs [144].

To summarize, macrophages in the tumor microenvironment are a major source of proangiogenic growth factors. Not only do they stimulate lymphangiogenesis through activation of endothelial cells, but they can also participate in this process by expressing LYVE-1 or becoming integral components of lymphatic vessels [146].

5.3. T-Cells. Recent research has led to a better understanding of the role of adaptive immune cells in the tumor 
microenvironment and first therapeutic options interfering with T-cell functions have successfully been US Food and Drug Administration (FDA) approved for antibody-based treatments in patients with advanced melanoma, for example, ipilimumab (see therapeutic approaches below).

A major attempt in development of immunological treatment strategies focuses on the identification of tumor-cell specific markers that may serve as therapy targets. Antigen recognition involves $\mathrm{CD} 8+\mathrm{T}$-cells recognizing tumor antigen [118]. Within the tumor microenvironment, two categories of CD8+ T-cells have been described. Some tumor tissues contain tumor-infiltrating T-cells, which secrete IFN- $\gamma$, whereas others lack T-cell infiltration and signs of inflammation. Whereas in the first group the tumor most likely inhibits the immune response, in the second group the immune system seems to ignore the ongoing tumor process (immune ignorance). The T-cell infiltrating phenotype has been shown for different types of cancer, including colorectal cancer [159, 160], renal cell carcinoma, melanoma, and ovarian cancer [161-164], and may have a positive prognostic value. A very good clinical outcome could be demonstrated for a high CD8+ T-cell to Fop3 $+\mathrm{T}_{\text {regs }}$ ratio in the ovarian cancer tumor microenvironment [165]. However, some melanomas still progress despite a T-cell infiltration, possibly related to a regress of the effectiveness of T-cells against tumor cells. This reduced effectiveness might be induced by the immunosuppressive tumor microenvironment [166]. The second group lacking tumor-infiltrating CD8+ T-cells was associated with an increased risk for metastasis into draining lymph nodes and decreased survival in dermal melanoma [161, 167].

Currently, the impact of T-cells on lymphangiogenesis and whether VEGF is involved in this context are mainly unknown. One study revealed that T-cells migrate responding to VEGF and that activated T-cells can express VEGF-R1 on their surface. Moreover, VEGF increased IL-10 secretion of these cells and might therefore direct chemotaxis and immune modulation of T-cells in tumor tissues [168].

5.4. B-Cells. Similar to T-cells, our knowledge on a potential role of B-cells in lymphangiogenesis is limited. Ruddell et al. reported B-cell accumulation in tumor draining lymph nodes, which induced lymphangiogenesis and increased lymphatic flow in $\mathrm{E} \mu-c-M y c$ transgenic mice [169]. These mice exhibited increased lymphatic metastasis of lymphoma and melanoma [170]. Harrell et al. made similar observations. In a melanoma mouse model, B-cells were important for lymphangiogenesis and increased lymphatic flow through tumor draining lymph nodes [171]. However, the underlying mechanisms still need to be investigated.

\section{Future Immunotherapeutic Strategies to Block Lymphangiogenesis and Prevent Lymphatic Metastasis}

New therapeutic approaches have made it into clinical treatment to some extent. Although many of them are interfering with immune cell function, a secondary effect on lymphangiogenesis is expected, as immune activation induces lymphangiogenesis by different factors mentioned above. Below the latest therapeutic approaches or ideas are listed which may be used on a regular basis in the future to improve cancer treatment.

VEGF Inhibiting Antibodies. One of the first antibodies interfering with VEGF function was bevacizumab (Avastin), which was FDA approved for treatment of metastatic colorectal carcinoma [22]. Only a few studies have been performed with explicit focus on lymphangiogenesis. Sunitinib, a small molecule interfering with VEGF-R1 and VEGF-R2, PDGF $\alpha$ and PDGF $\beta$, KIT receptor, and Flt3 receptor [172], was FDA approved in 2006 and is currently used for the treatment of metastatic renal cell carcinoma and gastrointestinal stromal tumors [173]. A similar molecule is sorafenib, interfering with VEGF-R2 and VEGF-R3, PDGF receptor $\beta$, and c-KIT receptor [174], and is FDA approved for advanced renal cell carcinoma [175]. Studies in mice revealed that, by using RNA interference to inhibit VEGF-C expression, the lymphangiogenesis, the number of lymph node metastasis has been reduced and the survival prolonged [176]. Interfering with VEGF-R3 resulted in similar observations [177]. A VEGF-D blocking antibody reduced lymphatic metastasis in mice [23].

In human colorectal cancer, it has been shown that cyclooxygenase 2 (COX2) (involved in production of prostaglandins [178]) and VEGF-C are coexpressed [179]. In a mice lung cancer model celecoxib, a selective COX2 inhibitor reduced lymphangiogenesis and lymph node metastasis [180] indicating that VEGF expression and thereby lymphangiogenesis might be associated with prostaglandins.

Due to the increasing number of new therapeutics interfering with VEGF function, we refer to excellent reviews which address VEGF inhibitors in depth, for example, that by Takahashi [181].

Programmed Death Ligand 1. PDL1 is an immune regulator, expressed on APCs and in $20-50 \%$ on human cancer cells [133, 137]. Tumor-induced PDL1 inhibits T-cell function and induces immune tolerance but also apoptosis of T-cells [182]. In contrast, it induces the expansion of $\mathrm{T}_{\text {regs }}$ [183]. Therefore, blocking this ligand on the tumor cells and on antigen presenting cells improves tumor defense and T-cells with anticancer properties restore their effector function [184]. However, severe side effects have been reported when interfering with the immune system [185].

Cancer Immunotherapy Using Dendritic Cells. Targeting DCs and performance of an adoptive transfer, for example, with antigen loaded DCs, may improve immunotherapy in the future. There are different ways to vaccine DCs by using tumor lysate, viral vectors, DNA plasmids, or antigen peptides [186]. The optimized vaccination and administration approaches (intralymphatic, intravenous, or intradermal, etc.) are subject of ongoing research to improve clinical outcomes [186]. Furthermore, the procedure is restricted by the DC maturation state and dose finding [186]. It is possible that DCs in vivo might become suppressive DCs, thus counteracting antitumor immune responses. Despite its 
pros and cons, DC vaccination is a promising field for future improvements in cancer therapy.

Genetically Modified Autologous T-Cells. Lately, there were first reports of patients who have been treated with an adoptive transfer of genetically modified autologous T-cells, which could improve certain B-cell malignancies $[187,188]$ or chronic lymphoid leukemia [189]. Thereby the T-cell antigen receptor was modified to target CD19 (expressed on Bcells) and a T-cell signaling molecule. First cases treated with these $\mathrm{T}$-cells revealed a complete remission, although accompanied by adverse events during treatment [187-189]. Taken together, these first studies are showing promising results from autologous T-cell transfers and might improve cancer treatment in the future.

Anti-CTLA4 Antibodies. In physiological conditions, T-cells are stimulated via CD28, which interacts with B7.1 and B7.2 on dendritic cells. Besides the "on button" CD28, T-cells express CTLA4, which can be regarded as "off button." CTLA4 serves as a coinhibitor on activated T-cells to regulate their immune response [183]. Anti-CTLA4 antibodies such as ipilimumab are immune modulatory biologics and are regarded as a milestone in the treatment of metastatic melanoma [183]. Ipilimumab was FDA approved in 2011. It is able to block the major inhibitor of activated T-cells CTLA4 and blocks the interaction to its ligand B7.1 and B7.2 expressed on antigen presenting cells [190]. T-cells are thereby effectively and long-term activated to fight against tumor cells. However, immune modulatory biologics may have severe side effects, due to excessive and autoaggressive effects of the immune system [191]. CTLA4 deficient mice die early as a result of an uncontrolled lymphocyte proliferation that leads to multiorgan destruction [192].

Interfering with CTLA4 can also induce immune suppressive and immune tolerance: the antibody CTLA4-Ig-RFP occupies the B7.1 and B7.2 receptor on DCs and thereby blocks its interaction with CD28 [193].

CCR7-CCL19/21. Interfering with the CCL21-CCR7 axis to reduce immune cell or tumor cell migration has been tried in different approaches. Antagonists of CCL21 seem to prevent the development of chronic graft versus host disease [194] or reduced allergic conjunctivitis by blocking CCR7 in mice [195]. Obstructing CCR7 expression at mRNA level in a murine tumor model inhibited lymph node metastasis and lymphangiogenesis [196]. Pretreatment with an allogenic melanoma-derived cell lysate was capable of upregulating CCR7 expression on therapeutic human tumor presenting DCs and inducing migration to the lymph node [197]. This knowledge might be used for future improvement of immunotherapy. However, all studies interfering with the CCR7 axis in humans to treat cancer and metastasis are still in very early stages.

\section{Conclusions}

Lymphangiogenesis is a very early step in lymphatic metastasis. It is regulated and promoted not only by the tumor cells themselves, but also by cells of the tumor microenvironment, including cancer-associated fibroblasts, mesenchymal stem cells, dendritic cells, or macrophages. Even the extracellular matrix as well as cytokines and growth factors are involved in the process of lymphangiogenesis and metastasis. Many mechanisms behind lymphangiogenesis in the tumor microenvironmental crosstalk are still incompletely understood. A better insight of the underlying mechanisms might improve future therapeutics to reduce lymphatic spread of cancer cells to the draining lymph nodes in order to increase the survival of cancer patients. A personalized and thereby optimized therapy interfering with the affected parts of the tumor microenvironment is a promising approach for future treatment of lymphatic metastasis and thus tumor related death.

\section{Conflict of Interests}

The authors declare that they have no conflict of interests.

\section{Authors' Contribution}

Simona L. Schlereth and Nasrin Refaian contributed equally to this work.

\section{Acknowledgments}

This work was supported by the German Research Foundation (HE 6743/2-1 to Ludwig M. Heindl; Priority Research Project SFB 643: B10, CU 47/6-1, CU 47/4-1 to Claus Cursiefen; CRC829 and CRC832 to Sandra Iden), the European Union (FP7 STRONG to Claus Cursiefen), German Cancer Aid (to Ludwig M. Heindl and Claus Cursiefen, emerging field of the Center of Integrated Oncology Cologne-Bonn), and the University of Cologne (GEROK Program to Simona L. Schlereth and Ludwig M. Heindl).

\section{References}

[1] J. D. Shields, M. Borsetti, H. Rigby et al., "Lymphatic density and metastatic spread in human malignant melanoma," British Journal of Cancer, vol. 90, no. 3, pp. 693-700, 2004.

[2] N. J. P. Beasley, R. Prevo, S. Banerji et al., "Intratumoral lymphangiogenesis and lymph node metastasis in head and neck cancer," Cancer Research, vol. 62, no. 5, pp. 1315-1320, 2002.

[3] M. W. Beckmann, G. Mehlhorn, F. Thiel, C. Breuel, P. A. Fasching, and S. Ackermann, "Therapiefortschritte beim primären Zervixkarzinom,” Deutsches Ärzteblatt, vol. 102, pp. A979-A986, 2005.

[4] E. Sundlisæter, A. Dicko, P. Ø. Sakariassen, K. Sondenaa, P. $\varnothing$. Enger, and R. Bjerkvig, "Lymphangiogenesis in colorectal cancer-prognostic and therapeutic aspects," International Journal of Cancer, vol. 121, no. 7, pp. 1401-1409, 2007.

[5] J. Bruce, D. C. Carter, and J. Fraser, "Patterns of recurrent disease in breast cancer," The Lancet, vol. 1, no. 7644, pp. 433-435, 1970.

[6] L. M. Heindl, C. Hofmann-Rummelt, W. Adler et al., "Prognostic significance of tumor-associated lymphangiogenesis in malignant melanomas of the conjunctiva," Ophthalmology, vol. 118, no. 12, pp. 2351-2360, 2011. 
[7] L. M. Heindl, C. Hofmann-Rummelt, W. Adler et al., “Tumorassociated lymphangiogenesis in the development of conjunctival melanoma," Investigative Ophthalmology \& Visual Science, vol. 52, no. 10, pp. 7074-7083, 2011.

[8] L. M. Heindl, C. Hofmann-Rummelt, W. Adler et al., “Tumorassociated lymphangiogenesis in the development of conjunctival squamous cell carcinoma," Ophthalmology, vol. 117, no. 4, pp. 649-658, 2010.

[9] L. M. Heindl, F. Bucher, G. O. Naumann, and C. Cursiefen, "Lack of ciliary body lymphatics in iridociliary melanocytoma," Graefe's Archive for Clinical and Experimental Ophthalmology, vol. 252, pp. 169-171, 2014.

[10] L. M. Heindl, T. N. Hofmann, W. Adler et al., "Intraocular tumor-associated lymphangiogenesis: a novel prognostic factor for ciliary body melanomas with extraocular extension?" Ophthalmology, vol. 117, no. 2, pp. 334-342, 2010.

[11] L. M. Heindl, T. N. Hofmann, H. L. J. Knorr et al., "Intraocular lymphangiogenesis in malignant melanomas of the ciliary body with extraocular extension," Investigative Ophthalmology \& Visual Science, vol. 50, no. 5, pp. 1988-1995, 2009.

[12] L. M. Heindl, T. N. Hofmann, F. Schrödl, L. M. Holbach, F. E. Kruse, and C. Cursiefen, "Intraocular lymphatics in ciliary body melanomas with extraocular extension: functional for lymphatic spread?" Archives of Ophthalmology, vol. 128, no. 8, pp. 1001-1008, 2010.

[13] L. M. Heindl, F. Schrödl, E. Lütjen-Drecoll, and C. Cursiefen, "Ciliary body lymphangiogenesis," Ophthalmology, vol. 120, no. 7, pp. e41-e42, 2013.

[14] M. Nagahashi, S. Ramachandran, O. M. Rashid, and K. Takabe, "Lymphangiogenesis: a new player in cancer progression," World Journal of Gastroenterology, vol. 16, no. 32, pp. 4003-4012, 2010.

[15] V. Joukov, K. Pajusola, A. Kaipainen et al., "A novel vascular endothelial growth factor, VEGF-C, is a ligand for the Flt4 (VEGFR-3) and KDR (VEGFR-2) receptor tyrosine kinases," The EMBO Journal, vol. 15, no. 2, pp. 290-298, 1996.

[16] M. J. Karkkainen and T. V. Petrova, "Vascular endothelial growth factor receptors in the regulation of angiogenesis and lymphangiogenesis," Oncogene, vol. 19, no. 49, pp. 5598-5605, 2000.

[17] S. F. Schoppmann, P. Birner, J. Stöckl et al., "Tumor-associated macrophages express lymphatic endothelial growth factors and are related to peritumoral lymphangiogenesis," The American Journal of Pathology, vol. 161, no. 3, pp. 947-956, 2002.

[18] C. Cursiefen, L. Chen, L. P. Borges et al., "VEGF-A stimulates lymphangiogenesis and hemangiogenesis in inflammatory neovascularization via macrophage recruitment," Journal of Clinical Investigation, vol. 113, no. 7, pp. 1040-1050, 2004.

[19] K. Maruyama, M. Ii, C. Cursiefen et al., "Inflammation-induced lymphangiogenesis in the cornea arises from CD11b-positive macrophages," The Journal of Clinical Investigation, vol. 115, no. 9, pp. 2363-2372, 2005.

[20] J. C. Becker, M. H. Andersen, D. Schrama, and P. Thor Straten, "Immune-suppressive properties of the tumor microenvironment," Cancer Immunology, Immunotherapy, vol. 62, no. 7, pp. 1137-1148, 2013.

[21] H. Ungefroren, S. Sebens, D. Seidl, H. Lehnert, and R. Hass, "Interaction of tumor cells with the microenvironment," Cell Communication and Signaling, vol. 9, article 18, 2011.

[22] N. Ferrara, K. J. Hillan, H.-P. Gerber, and W. Novotny, "Discovery and development of bevacizumab, an anti-VEGF antibody for treating cancer," Nature Reviews Drug Discovery, vol. 3, no. 5, pp. 391-400, 2004.

[23] S. A. Stacker, C. Caesar, M. E. Baldwin et al., "VEGF-D promotes the metastatic spread of tumor cells via the lymphatics," Nature Medicine, vol. 7, no. 2, pp. 186-191, 2001.

[24] T. V. Byzova, C. K. Goldman, J. Jankau et al., "Adenovirus encoding vascular endothelial growth factor-D induces tissuespecific vascular patterns in vivo," Blood, vol. 99, no. 12, pp. 4434-4442, 2002.

[25] T. Tsurusaki, S. Kanda, H. Sakai et al., "Vascular endothelial growth factor-C expression in human prostatic carcinoma and its relationship to lymph node metastasis," British Journal of Cancer, vol. 80, no. 1-2, pp. 309-313, 1999.

[26] Y. Yonemura, Y. Endo, H. Fujita et al., "Role of vascular endothelial growth factor $\mathrm{C}$ expression in the development of lymph node metastasis in gastric cancer," Clinical Cancer Research, vol. 5, no. 7, pp. 1823-1829, 1999.

[27] K. Akagi, Y. Ikeda, M. Miyazaki et al., "Vascular endothelial growth factor-C (VEGF-C) expression in human colorectal cancer tissues," The British Journal of Cancer, vol. 83, no. 7, pp. 887-891, 2000.

[28] T. Niki, S. Iba, M. Tokunou, T. Yamada, Y. Matsuno, and S. Hirohashi, "Expression of vascular endothelial growth factors $\mathrm{A}, \mathrm{B}, \mathrm{C}$, and D and their relationships to lymph node status in lung adenocarcinoma," Clinical Cancer Research, vol. 6, no. 6, pp. 2431-2439, 2000.

[29] I. Hashimoto, J. Kodama, N. Seki et al., "Vascular endothelial growth factor-C expression and its relationship to pelvic lymph node status in invasive cervical cancer," British Journal of Cancer, vol. 85, no. 1, pp. 93-97, 2001.

[30] C. Schietroma, F. Cianfarani, P. M. Lacal et al., "Vascular endothelial growth factor-C expression correlates with lymph node localization of human melanoma metastases," Cancer, vol. 98, no. 4, pp. 789-797, 2003.

[31] M. Skobe, T. Hawighorst, D. G. Jackson et al., "Induction of tumor lymphangiogenesis by VEGF-C promotes breast cancer metastasis," Nature Medicine, vol. 7, no. 2, pp. 192-198, 2001.

[32] A. Issa, T. X. Le, A. N. Shoushtari, J. D. Shields, and M. A. Swartz, "Vascular endothelial growth factor-C and C-C chemokine receptor 7 in tumor cell-lymphatic cross-talk promote invasive phenotype," Cancer Research, vol. 69, no. 1, pp. 349-357, 2009.

[33] L. Quagliata, S. Klusmeier, N. Cremers et al., "Inhibition of VEGFR-3 activation in tumor-draining lymph nodes suppresses the outgrowth of lymph node metastases in the MT-450 syngeneic rat breast cancer model," Clinical \& Experimental Metastasis, vol. 31, pp. 351-365, 2014.

[34] R. S. Saad, L. Kordunsky, Y. L. Liu, K. L. Denning, H. A. Kandil, and J. F. Silverman, "Lymphatic microvessel density as prognostic marker in colorectal cancer," Modern Pathology, vol. 19, no. 10, pp. 1317-1323, 2006.

[35] S. Hirakawa, S. Kodama, R. Kunstfeld, K. Kajiya, L. F. Brown, and M. Detmar, "VEGF-A induces tumor and sentinel lymph node lymphangiogenesis and promotes lymphatic metastasis," Journal of Experimental Medicine, vol. 201, no. 7, pp. 1089-1099, 2005.

[36] T. Tammela and K. Alitalo, "Lymphangiogenesis: molecular mechanisms and future promise," Cell, vol. 140, no. 4, pp. 460476, 2010.

[37] S. S. Dadras, B. Lange-Asschenfeldt, P. Velasco et al., "Tumor lymphangiogenesis predicts melanoma metastasis to sentinel lymph nodes," Modern Pathology, vol. 18, no. 9, pp. 1232-1242, 2005. 
[38] J. Holash, P. C. Maisonpierre, D. Compton et al., "Vessel cooption, regression, and growth in tumors mediated by angiopoietins and VEGF,' Science, vol. 284, no. 5422, pp. 19941998, 1999.

[39] H. Huang, A. Bhat, G. Woodnutt, and R. Lappe, "Targeting the ANGPT-TIE2 pathway in malignancy," Nature Reviews Cancer, vol. 10 , no. 8, pp. 575-585, 2010.

[40] W. Sun, "Angiogenesis in metastatic colorectal cancer and the benefits of targeted therapy," Journal of Hematology \& Oncology, vol. 5, article 63, 2012.

[41] S. Davis, T. H. Aldrich, P. F. Jones et al., "Isolation of angiopoietin-1, a ligand for the TIE2 receptor, by secretion-trap expression cloning," Cell, vol. 87, no. 7, pp. 1161-1169, 1996.

[42] C. Scavelli, A. Vacca, G. Di Pietro, F. Dammacco, and D. Ribatti, "Crosstalk between angiogenesis and lymphangiogenesis in tumor progression," Leukemia, vol. 18, no. 6, pp. 1054-1058, 2004.

[43] P. C. Maisonpierre, C. Suri, P. F. Jones et al., "Angiopoietin-2, a natural antagonist for $\mathrm{Tie}_{2}$ that disrupts in vivo angiogenesis," Science, vol. 277, no. 5322, pp. 55-60, 1997.

[44] P. Schulz, C. Fischer, K. M. Detjen et al., "Angiopoietin-2 drives lymphatic metastasis of pancreatic cancer," FASEB Journal, vol. 25, no. 10, pp. 3325-3335, 2011.

[45] R. Cao, M. A. Björndahl, P. Religa et al., "PDGF-BB induces intratumoral lymphangiogenesis and promotes lymphatic metastasis," Cancer Cell, vol. 6, no. 4, pp. 333-345, 2006.

[46] L. K. Chang, G. Garcia-Cardeña, F. Farnebo et al., "Dosedependent response of FGF-2 for lymphangiogenesis," Proceedings of the National Academy of Sciences of the United States of America, vol. 101, no. 32, pp. 11658-11663, 2004.

[47] C. M. Yoon, B. S. Hong, H. G. Moon et al., "Sphingosine1-phosphate promotes lymphangiogenesis by stimulating S1P1/Gi/PLC/Ca ${ }^{2+}$ signaling pathways," Blood, vol. 112, no. 4, pp. 1129-1138, 2008.

[48] R. Cao, M. A. Björndahl, M. I. Gallego et al., "Hepatocyte growth factor is a lymphangiogenic factor with an indirect mechanism of action," Blood, vol. 107, no. 9, pp. 3531-3536, 2006.

[49] S. Podgrabinska, P. Braun, P. Velasco et al., "Molecular characterization of lymphatic endothelial cells," Proceedings of the National Academy of Sciences of the United States of America, vol. 99, no. 25, pp. 16069-16074, 2002.

[50] M. Miyahara, J.-I. Tanuma, K. Sugihara, and I. Semba, “Tumor lymphangiogenesis correlates with lymph node metastasis and clinicopathologic parameters in oral squamous cell carcinoma," Cancer, vol. 110, no. 6, pp. 1287-1294, 2007.

[51] T. Sasahira, N. Ueda, K. Yamamoto et al., "Prox1 and FOXC2 act as regulators of lymphangiogenesis and angiogenesis in oral squamous cell carcinoma," PloS ONE, vol. 9, Article ID e92534, 2014.

[52] J. D. Shields, M. E. Fleury, C. Yong, A. A. Tomei, G. J. Randolph, and M. A. Swartz, "Autologous chemotaxis as a mechanism of tumor cell homing to lymphatics via interstitial flow and autocrine CCR7 signaling," Cancer Cell, vol. 11, no. 6, pp. 526538, 2007.

[53] P. J. Sarvaiya, D. Guo, I. Ulasov, P. Gabikian, and M. S. Lesniak, "Chemokines in tumor progression and metastasis," Oncotarget, vol. 4, pp. 2171-2185, 2013.

[54] R. M. Steinman, M. Pack, and K. Inaba, "Dendritic cells in the T-cell areas of lymphoid organs," Immunological Reviews, vol. 156, pp. 25-37, 1997.
[55] Y. Ding, Y. Shimada, M. Maeda et al., "Association of CC chemokine receptor 7 with lymph node metastasis of esophageal squamous cell carcinoma," Clinical Cancer Research, vol. 9, no. 9, pp. 3406-3412, 2003.

[56] H. Takeuchi, A. Fujimoto, M. Tanaka, T. Yamano, E. Hsueh, and D. S. B. Hoon, "CCL21 chemokine regulates chemokine receptor CCR7 bearing malignant melanoma cells," Clinical Cancer Research, vol. 10, no. 7, pp. 2351-2358, 2004.

[57] K. Mashino, N. Sadanaga, H. Yamaguchi et al., "Expression of chemokine receptor CCR7 is associated with lymph node metastasis of gastric carcinoma," Cancer Research, vol. 62, no. 10, pp. 2937-2941, 2002.

[58] S. López-Giral, N. E. Quintana, M. Cabrerizo et al., "Chemokine receptors that mediate $\mathrm{B}$ cell homing to secondary lymphoid tissues are highly expressed in B cell chronic lymphocytic leukemia and non-Hodgkin lymphomas with widespread nodular dissemination," Journal of Leukocyte Biology, vol. 76, no. 2, pp. 462-471, 2004.

[59] P. Li, F. Liu, L. Sun et al., "Chemokine receptor 7 promotes cell migration and adhesion in metastatic squamous cell carcinoma of the head and neck by activating integrin $\alpha \mathrm{v} \beta 3$," International Journal of Molecular Medicine, vol. 27, no. 5, pp. 679-687, 2011.

[60] Y. Li, X. Qiu, S. Zhang, Q. Zhang, and E. Wang, "Hypoxia induced CCR7 expression via HIF- $1 \alpha$ and HIF- $2 \alpha$ correlates with migration and invasion in lung cancer cells," Cancer Biology and Therapy, vol. 8, no. 4, pp. 322-330, 2009.

[61] P. Sui, P. Hu, T. Zhang, X. Zhang, Q. Liu, and J. Du, "High expression of CXCR-2 correlates with lymph node metastasis and predicts unfavorable prognosis in resected esophageal carcinoma," Medical Oncology, vol. 31, article 809, 2014.

[62] A. Müller, B. Homey, H. Soto et al., "Involvement of chemokine receptors in breast cancer metastasis," Nature, vol. 410, no. 6824, pp. 50-56, 2001.

[63] J. Ying, Q. Xu, G. Zhang, B. Liu, and L. Zhu, "The expression of CXCL12 and CXCR4 in gastric cancer and their correlation to lymph node metastasis," Medical Oncology, vol. 29, no. 3, pp. 1716-1722, 2012.

[64] M. Arya, H. R. H. Patel, C. McGurk et al., "The importance of the CXCL12-CXCR4 chemokine ligand-receptor interaction in prostate cancer metastasis," Journal of Experimental Therapeutics and Oncology, vol. 4, no. 4, pp. 291-303, 2004.

[65] S. Scala, P. Giuliano, P. A. Ascierto et al., "Human melanoma metastases express functional CXCR4," Clinical Cancer Research, vol. 12, no. 8, pp. 2427-2433, 2006.

[66] R. Franco, G. Botti, M. Mascolo et al., "CXCR4-CXCL12 and VEGF correlate to uveal melanoma progression," Frontiers in Bioscience-Elite, vol. 2, no. 1, pp. 13-21, 2010.

[67] C. Savarin-Vuaillat and R. M. Ransohoff, "Chemokines and chemokine receptors in neurological disease: raise, retain, or reduce?” Neurotherapeutics, vol. 4, no. 4, pp. 590-601, 2007.

[68] T. Murakami, W. Maki, A. R. Cardones et al., "Expression of CXC chemokine receptor- 4 enhances the pulmonary metastatic potential of murine B16 melanoma cells," Cancer Research, vol. 62, no. 24, pp. 7328-7334, 2002.

[69] B.-C. Zhao, Z.-J. Wang, W.-Z. Mao et al., "CXCR4/SDF-1 axis is involved in lymph node metastasis of gastric carcinoma," World Journal of Gastroenterology, vol. 17, no. 19, pp. 2389-2396, 2011.

[70] Y. X. Sun, J. Wang, C. E. Shelburne et al., "Expression of CXCR4 and CXCL12 (SDF-1) in human prostate cancers (PCa) in vivo," Journal of Cellular Biochemistry, vol. 89, no. 3, pp. 462-473, 2003. 
[71] K. Kawada, M. Sonoshita, H. Sakashita et al., "Pivotal role of CXCR3 in melanoma cell metastasis to lymph nodes," Cancer Research, vol. 64, no. 11, pp. 4010-4017, 2004.

[72] J. Campisi, "Aging, cellular senescence, and cancer," Annual Review of Physiology, vol. 75, pp. 685-705, 2013.

[73] P. Castro, D. Giri, D. Lamb, and M. Ittmann, "Cellular senescence in the pathogenesis of benign prostatic hyperplasia," The Prostate, vol. 55, no. 1, pp. 30-38, 2003.

[74] M. Collado and M. Serrano, "Senescence in tumours: evidence from mice and humans," Nature Reviews Cancer, vol. 10, no. 1, pp. 51-57, 2010.

[75] C. Michaloglou, L. C. W. Vredeveld, M. S. Soengas et al., "BRAFE600-associated senescence-like cell cycle arrest of human naevi," Nature, vol. 436, no. 7051, pp. 720-724, 2005.

[76] L. C. W. Vredeveld, P. A. Possik, M. A. Smit et al., "Abrogation of BRAFV600E-induced senescence by PI3K pathway activation contributes to melanomagenesis," Genes and Development, vol. 26, no. 10, pp. 1055-1069, 2012.

[77] M. C. Velarde, M. Demaria, and J. Campisi, "Senescent cells and their secretory phenotype as targets for cancer therapy," Interdisciplinary Topics in Gerontology, vol. 38, pp. 17-27, 2013.

[78] W. Xue, L. Zender, C. Miething et al., "Senescence and tumour clearance is triggered by $\mathrm{p} 53$ restoration in murine liver carcinomas," Nature, vol. 445, no. 7128, pp. 656-660, 2007.

[79] S. Rajagopalan and E. O. Long, "Cellular senescence induced by CD158d reprograms natural killer cells to promote vascular remodeling.", Proceedings of the National Academy of Sciences of the United States of America, vol. 109, no. 50, pp. 20596-20601, 2012.

[80] E. Alspach, Y. Fu, and S. A. Stewart, "Senescence and the protumorigenic stroma," Critical Reviews in Oncogenesis, vol. 18, pp. 549-558, 2013.

[81] R. Kalluri, "Basement membranes: structure, assembly and role in tumour angiogenesis," Nature Reviews Cancer, vol. 3, no. 6, pp. 422-433, 2003.

[82] R. Kalluri and M. Zeisberg, "Fibroblasts in cancer," Nature Reviews Cancer, vol. 6, no. 5, pp. 392-401, 2006.

[83] M. M. Mueller and N. E. Fusenig, "Friends or foes-bipolar effects of the tumour stroma in cancer," Nature Reviews Cancer, vol. 4, no. 11, pp. 839-849, 2004.

[84] M. M. Mueller, T. Werbowetski, and R. F. Del Maestro, "Soluble factors involved in glioma invasion," Acta Neurochirurgica, vol. 145, no. 11, pp. 999-1008, 2003.

[85] W. G. Stetler-Stevenson and A. E. Yu, "Proteases in invasion: matrix metalloproteinases," Seminars in Cancer Biology, vol. 11, no. 2, pp. 143-152, 2001.

[86] F. Mbeunkui and D. J. Johann Jr., "Cancer and the tumor microenvironment: a review of an essential relationship," Cancer Chemotherapy and Pharmacology, vol. 63, no. 4, pp. 571-582, 2009.

[87] L. F. Brown, A. J. Guidi, S. J. Schnitt et al., "Vascular stroma formation in carcinoma in situ, invasive carcinoma, and metastatic carcinoma of the breast," Clinical Cancer Research, vol. 5, no. 5, pp. 1041-1056, 1999.

[88] Z. Werb, "ECM and cell surface proteolysis: regulating cellular ecology," Cell, vol. 91, no. 4, pp. 439-442, 1997.

[89] J. Krstic and J. F. Santibanez, "Transforming growth factorbeta and matrix metalloproteinases: functional interactions in tumor stroma-infiltrating myeloid cells," The Scientific World Journal, vol. 2014, Article ID 521754, 14 pages, 2014.
[90] T. C. Laurent and J. R. E. Fraser, "Hyaluronan," The FASEB Journal, vol. 6, no. 7, pp. 2397-2404, 1992.

[91] S. Banerji, J. Ni, S.-X. Wang et al., "LYVE-1, a new homologue of the CD44 glycoprotein, is a lymph-specific receptor for hyaluronan," Journal of Cell Biology, vol. 144, no. 4, pp. 789-801, 1999.

[92] N. Itano, L. Zhuo, and K. Kimata, "Impact of the hyaluronanrich tumor microenvironment on cancer initiation and progression," Cancer Science, vol. 99, no. 9, pp. 1720-1725, 2008.

[93] T. D. Tlsty and P. W. Hein, "Know thy neighbor: stromal cells can contribute oncogenic signals," Current Opinion in Genetics and Development, vol. 11, no. 1, pp. 54-59, 2001.

[94] B. Elenbaas and R. A. Weinberg, "Heterotypic signaling between epithelial tumor cells and fibroblasts in carcinoma formation," Experimental Cell Research, vol. 264, no. 1, pp. 169$184,2001$.

[95] P. Garin-Chesa, L. J. Old, and W. J. Rettig, "Cell surface glycoprotein of reactive stromal fibroblasts as a potential antibody target in human epithelial cancers," Proceedings of the National Academy of Sciences of the United States of America, vol. 87, no. 18, pp. 7235-7239, 1990.

[96] D. Lazard, X. Sastre, M. G. Frid, M. A. Glukhova, J.-P. Thiery, and V. E. Koteliansky, "Expression of smooth muscle-specific proteins in myoepithelium and stromal myofibroblasts of normal and malignant human breast tissue," Proceedings of the National Academy of Sciences of the United States of America, vol. 90, no. 3, pp. 999-1003, 1993.

[97] H. Y. Chang, J.-T. Chi, S. Dudoit et al., "Diversity, topographic differentiation, and positional memory in human fibroblasts," Proceedings of the National Academy of Sciences of the United States of America, vol. 99, no. 20, pp. 12877-12882, 2002.

[98] M. Shimoda, K. T. Mellody, and A. Orimo, "Carcinomaassociated fibroblasts are a rate-limiting determinant for tumour progression," Seminars in Cell and Developmental Biology, vol. 21, no. 1, pp. 19-25, 2010.

[99] M. Bauer, G. Su, C. Casper, R. He, W. Rehrauer, and A. Friedl, "Heterogeneity of gene expression in stromal fibroblasts of human breast carcinomas and normal breast," Oncogene, vol. 29, no. 12, pp. 1732-1740, 2010.

[100] O. de Wever, Q.-D. Nguyen, L. van Hoorde et al., "Tenascin$\mathrm{C}$ and $\mathrm{SF} / \mathrm{HGF}$ produced by myofibroblasts in vitro provide convergent pro-invasive signals to human colon cancer cells through RhoA and Rac," The FASEB Journal, vol. 18, no. 9, pp. 1016-1018, 2004.

[101] O. de Wever and M. Mareel, "Role of tissue stroma in cancer cell invasion," The Journal of Pathology, vol. 200, no. 4, pp. 429-447, 2003.

[102] S. Semba, Y. Kodama, K. Ohnuma et al., "Direct cancer-stromal interaction increases fibroblast proliferation and enhances invasive properties of scirrhous-type gastric carcinoma cells," British Journal of Cancer, vol. 101, no. 8, pp. 1365-1373, 2009.

[103] D. Liao, Y. Luo, D. Markowitz, R. Xiang, and R. A. Reisfeld, "Cancer associated fibroblasts promote tumor growth and metastasis by modulating the tumor immune microenvironment in a 4T1 murine breast cancer model," PLoS ONE, vol. 4, no. 11, Article ID e7965, 2009.

[104] A. Orimo, P. B. Gupta, D. C. Sgroi et al., "Stromal fibroblasts present in invasive human breast carcinomas promote tumor growth and angiogenesis through elevated SDF-1/CXCL12 secretion," Cell, vol. 121, no. 3, pp. 335-348, 2005.

[105] Y. Zhang, H. Tang, J. Cai et al., "Ovarian cancer-associated fibroblasts contribute to epithelial ovarian carcinoma metastasis 
by promoting angiogenesis, lymphangiogenesis and tumor cell invasion," Cancer Letters, vol. 303, no. 1, pp. 47-55, 2011.

[106] B. Pula, A. Jethon, A. Piotrowska et al., "Podoplanin expression by cancer-associated fibroblasts predicts poor outcome in invasive ductal breast carcinoma," Histopathology, vol. 59, no. 6, pp. 1249-1260, 2011.

[107] E. L. Spaeth, J. L. Dembinski, A. K. Sasser et al., "Mesenchymal stem cell transition to tumor-associated fibroblasts contributes to fibrovascular network expansion and tumor progression," PLoS ONE, vol. 4, no. 4, Article ID e4992, 2009.

[108] J. Guan and J. Chen, "Mesenchymal stem cells in the tumor microenvironment," Biomedical Reports, vol. 1, pp. 517-521, 2013.

[109] B. M. Beckermann, G. Kallifatidis, A. Groth et al., "VEGF expression by mesenchymal stem cells contributes to angiogenesis in pancreatic carcinoma," British Journal of Cancer, vol. 99, no. 4, pp. 622-631, 2008.

[110] K. Buttler, M. Badar, V. Seiffart et al., "De novo hem- and lymphangiogenesis by endothelial progenitor and mesenchymal stem cells in immunocompetent mice," Cellular and Molecular Life Sciences, vol. 71, no. 8, pp. 1513-1527, 2014.

[111] K. Kajiya, S. Hirakawa, B. Ma, I. Drinnenberg, and M. Detmar, "Hepatocyte growth factor promotes lymphatic vessel formation and function," The EMBO Journal, vol. 24, no. 16, pp. 28852895, 2005.

[112] M. T. Dellinger and R. A. Brekken, "Phosphorylation of Akt and ERK1/2 is required for VEGF-A/VEGFR2-induced proliferation and migration of lymphatic endothelium," PLOS ONE, vol. 6, no. 12, Article ID e28947, 2011.

[113] S. Shinriki, H. Jono, M. Ueda et al., "Interleukin-6 signalling regulates vascular endothelial growth factor- $\mathrm{C}$ synthesis and lymphangiogenesis in human oral squamous cell carcinoma," The Journal of Pathology, vol. 225, no. 1, pp. 142-150, 2011.

[114] Y. H. Huang, H. Y. Yang, Y. F. Hsu, P. T. Chiu, G. Ou, and M. J. Hsu, "Src contributes to IL6-induced vascular endothelial growth factor-C expression in lymphatic endothelial cells," Angiogenesis, vol. 17, no. 2, pp. 407-418, 2014.

[115] C. Conrad, H. Niess, R. Huss et al., "Multipotent mesenchymal stem cells acquire a lymphendothelial phenotype and enhance lymphatic regeneration in vivo," Circulation, vol. 119, no. 2, pp. 281-289, 2009.

[116] A. E. Karnoub, A. B. Dash, A. P. Vo et al., "Mesenchymal stem cells within tumour stroma promote breast cancer metastasis," Nature, vol. 449, no. 7162, pp. 557-563, 2007.

[117] M. B. Fuertes, A. K. Kacha, J. Kline et al., "Host type I IFN signals are required for antitumor $\mathrm{CD}^{+} \mathrm{T}$ cell responses through $\mathrm{CD} 8 \alpha^{+}$dendritic cells," The Journal of Experimental Medicine, vol. 208, no. 10, pp. 2005-2016, 2011.

[118] T. F. Gajewski, H. Schreiber, and Y. X. Fu, "Innate and adaptive immune cells in the tumor microenvironment," Nature Immunology, vol. 14, pp. 1014-1022, 2013.

[119] K. Steinbrink, M. Wölfl, H. Jonuleit, J. Knop, and A. H. Enk, "Induction of tolerance by IL-10-treated dendritic cells," The Journal of Immunology, vol. 159, no. 10, pp. 4772-4780, 1997.

[120] K. Palucka and J. Banchereau, "Cancer immunotherapy via dendritic cells," Nature Reviews Cancer, vol. 12, no. 4, pp. 265277, 2012.

[121] N. J. Bahlis, A. M. King, D. Kolonias et al., "CD28-mediated regulation of multiple myeloma cell proliferation and survival," Blood, vol. 109, no. 11, pp. 5002-5010, 2007.

[122] S. Wei, I. Kryczek, L. Zou et al., "Plasmacytoid dendritic cells induce $\mathrm{CD}^{+}$regulatory T cells in human ovarian carcinoma," Cancer Research, vol. 65, no. 12, pp. 5020-5026, 2005.
[123] T. J. Curiel, P. Cheng, P. Mottram et al., "Dendritic cell subsets differentially regulate angiogenesis in human ovarian cancer," Cancer Research, vol. 64, no. 16, pp. 5535-5538, 2004.

[124] A. Thiel, R. Kesselring, R. Pries, N. Wittkopf, A. Puzik, and B. Wollenberg, "Plasmacytoid dendritic cell subpopulations in head and neck squamous cell carcinoma," Oncology Reports, vol. 26, no. 3, pp. 615-620, 2011.

[125] I. Treilleux, J.-Y. Blay, N. Bendriss-Vermare et al., "Dendritic cell infiltration and prognosis of early stage breast cancer," Clinical Cancer Research, vol. 10, no. 22, pp. 7466-7474, 2004.

[126] R.-C. Ji, "Macrophages are important mediators of either tumor- or inflammation-induced lymphangiogenesis," Cellular and Molecular Life Sciences, vol. 69, no. 6, pp. 897-914, 2012.

[127] S. Sozzani, M. Rusnati, E. Riboldi, S. Mitola, and M. Presta, "Dendritic cell-endothelial cell cross-talk in angiogenesis," Trends in Immunology, vol. 28, no. 9, pp. 385-392, 2007.

[128] E. Gottfried, M. Kreutz, S. Haffner et al., "Differentiation of human tumour-associated dendritic cells into endotheliallike cells: an alternative pathway of tumour angiogenesis," Scandinavian Journal of Immunology, vol. 65, no. 4, pp. 329-335, 2007.

[129] J. R. Conejo-Garcia, F. Benencia, M.-C. Courreges et al., "Tumor-infiltrating dendritic cell precursors recruited by a $\beta$ defensin contribute to vasculogenesis under the influence of Vegf-A," Nature Medicine, vol. 10, no. 9, pp. 950-958, 2004.

[130] D. I. Gabrilovich, T. Ishida, S. Nadaf, J. E. Ohm, and D. P. Carbone, "Antibodies to vascular endothelial growth factor enhance the efficacy of cancer immunotherapy by improving endogenous dendritic cell function," Clinical Cancer Research, vol. 5, no. 10, pp. 2963-2970, 1999.

[131] L. Chen, P. Hamrah, C. Cursiefen et al., "Vascular endothelial growth factor receptor-3 mediates induction of corneal alloimmunity," Nature Medicine, vol. 10, no. 8, pp. 813-815, 2004.

[132] M. Darash-Yahana, E. Pikarsky, R. Abramovitch et al., "Role of high expression levels of CXCR4 in tumor growth, vascularization, and metastasis," FASEB Journal, vol. 18, no. 11, pp. 12401242, 2004.

[133] H. Dong, S. E. Strome, D. R. Salomao et al., “Tumor-associated B7-H1 promotes T-cell apoptosis: a potential mechanism of immune evasion," Nature Medicine, vol. 8, no. 8, pp. 793-800, 2002.

[134] J. A. Brown, D. M. Dorfman, F.-R. Ma et al., "Blockade of programmed death-1 ligands on dendritic cells enhances $\mathrm{T}$ cell activation and cytokine production," Journal of Immunology, vol. 170, no. 3, pp. 1257-1266, 2003.

[135] L. Chen, "Co-inhibitory molecules of the B7-CD28 family in the control of T-cell immunity," Nature Reviews Immunology, vol. 4, no. 5, pp. 336-347, 2004.

[136] W. Yang, H. Li, P. W. Chen et al., "PD-L1 expression on human ocular cells and its possible role in regulating immune-mediated ocular inflammation," Investigative Ophthalmology and Visual Science, vol. 50, no. 1, pp. 273-280, 2009.

[137] S. T. Haile, J. J. Bosch, N. I. Agu et al., “Tumor cell programmed death ligand 1-mediated $\mathrm{T}$ cell suppression is overcome by coexpression of CD80," Journal of Immunology, vol. 186, no. 12, pp. 6822-6829, 2011.

[138] A. S. Mansfield, P. Heikkila, K. von Smitten, J. Vakkila, and M. Leidenius, "Metastasis to sentinel lymph nodes in breast cancer is associated with maturation arrest of dendritic cells and poor co-localization of dendritic cells and $\mathrm{CD}^{+} \mathrm{T}$ cells," Virchows Archiv, vol. 459, no. 4, pp. 391-398, 2011. 
[139] M. E. Polak, P. Johnson, S. Di Palma et al., "Presence and maturity of dendritic cells in melanoma lymph node metastases," The Journal of Pathology, vol. 207, no. 1, pp. 83-90, 2005.

[140] A. Kusume, T. Sasahira, Y. Luo et al., "Suppression of dendritic cells by HMGB1 is associated with lymph node metastasis of human colon cancer," Pathobiology, vol. 76, no. 4, pp. 155-162, 2009.

[141] S. Ohashi, S. Okamura, F. Urano, and M. Maeda, "Clinicopathological variables associated with lymph node metastasis in submucosal invasive gastric cancer," Gastric Cancer, vol. 10, no. 4, pp. 241-250, 2007.

[142] W. Vermi, A. Micheletti, S. Lonardi et al., "slanDCs selectively accumulate in carcinoma-draining lymph nodes and marginate metastatic cells," Nature Communications, vol. 5, article 3029, 2014.

[143] F. G. Gomes, F. Nedel, A. M. Alves, J. E. Nör, and S. B. C. Tarquinio, "Tumor angiogenesis and lymphangiogenesis: tumor/endothelial crosstalk and cellular/microenvironmental signaling mechanisms," Life Sciences, vol. 92, no. 2, pp. 101-107, 2013.

[144] C. E. Lewis and J. W. Pollard, "Distinct role of macrophages in different tumor microenvironments," Cancer Research, vol. 66, no. 2, pp. 605-612, 2006.

[145] V. Riabov, A. Gudima, N. Wang, A. Mickley, A. Orekhov, and J. Kzhyshkowska, "Role of tumor associated macrophages in tumor angiogenesis and lymphangiogenesis," Frontiers in Physiology, vol. 5, article 75, 2014.

[146] D. Kerjaschki, "The crucial role of macrophages in lymphangiogenesis," The Journal of Clinical Investigation, vol. 115, no. 9, pp. 2316-2319, 2005.

[147] K. Schledzewski, M. Falkowski, G. Moldenhauer et al., "Lympathic endothelium-specific hyaluronan receptor LYVE-1 is expressed by stabilin-1+, F4/80+, CD11b+ macropahages in malignant tumours and wound healing tissue in vivo and in bone marrow cultures in vitro: implications for the assessment of lymphangiogenesis," Journal of Pathology, vol. 209, no. 1, pp. 67-77, 2006.

[148] A. Zumsteg, V. Baeriswyl, N. Imaizumi, R. Schwendener, C. Rüegg, and G. Christofori, "Myeloid cells contribute to tumor lymphangiogenesis," PLoS ONE, vol. 4, no. 9, Article ID e7067, 2009.

[149] I. H. G. Bronkhorst, L. V. Ly, E. S. Jordanova et al., "Detection of M2-macrophages in uveal melanoma and relation with survival," Investigative Ophthalmology \& Visual Science, vol. 52, no. 2, pp. 643-650, 2011.

[150] R. D. Leek, C. E. Lewis, R. Whitehouse, M. Greenall, J. Clarke, and A. L. Harris, "Association of macrophage infiltration with angiogenesis and prognosis in invasive breast carcinoma," Cancer Research, vol. 56, no. 20, pp. 4625-4629, 1996.

[151] A. Nishie, M. Ono, T. Shono et al., "Macrophage infiltration and heme oxygenase-1 expression correlate with angiogenesis in human gliomas," Clinical Cancer Research, vol. 5, no. 5, pp. 1107-1113, 1999.

[152] H. Torisu, M. Ono, H. Kiryu et al., "Macrophage infiltration correlates with tumor stage and angiogenesis in human malignant melanoma: possible involvement of TNFalpha and IL-lalpha," International Journal of Cancer, vol. 85, pp. 182-188, 2000.

[153] D. Moussai, H. Mitsui, J. S. Pettersen et al., "The human cutaneous squamous cell carcinoma microenvironment is characterized by increased lymphatic density and enhanced expression of macrophage-derived VEGF-C," Journal of Investigative Dermatology, vol. 131, no. 1, pp. 229-236, 2011.
[154] M. S. Kluger and O. R. Colegio, "Lymphangiogenesis linked to VEGF-C from tumor-associated macrophages: accomplices to metastasis by cutaneous squamous cell carcinoma," Journal of Investigative Dermatology, vol. 131, no. 1, pp. 17-19, 2011.

[155] L. V. Ly, A. Baghat, M. Versluis et al., "In aged mice, outgrowth of intraocular melanoma depends on proangiogenic M2-type macrophages," Journal of Immunology, vol. 185, no. 6, pp. 34813488, 2010.

[156] T. Mäkitie, P. Summanen, A. Tarkkanen, and T. Kivelä, “Tumorinfiltrating macrophages (CD68 ${ }^{+}$cells) and prognosis in malignant uveal melanoma," Investigative Ophthalmology and Visual Science, vol. 42, no. 7, pp. 1414-1421, 2001.

[157] J. A. Nagy, E. Vasile, D. Feng et al., "Vascular permeability factor/vascular endothelial growth factor induces lymphangiogenesis as well as angiogenesis," The Journal of Experimental Medicine, vol. 196, no. 11, pp. 1497-1506, 2002.

[158] O. Fainaru, N. Almog, C. W. Yung et al., "Tumor growth and angiogenesis are dependent on the presence of immature dendritic cells," The FASEB Journal, vol. 24, no. 5, pp. 1411-1418, 2010.

[159] F. Pagès, A. Berger, M. Camus et al., "Effector memory T cells, early metastasis, and survival in colorectal cancer," New England Journal of Medicine, vol. 353, no. 25, pp. 2654-2666, 2005.

[160] J. Galon, A. Costes, F. Sanchez-Cabo et al., “Type, density, and location of immune cells within human colorectal tumors predict clinical outcome," Science, vol. 313, no. 5795, pp. 19601964, 2006.

[161] F. Azimi, R. A. Scolyer, P. Rumcheva et al., “Tumor-infiltrating lymphocyte grade is an independent predictor of sentinel lymph node status and survival in patients with cutaneous melanoma," Journal of Clinical Oncology, vol. 30, no. 21, pp. 2678-2683, 2012.

[162] B. Kreike, M. van Kouwenhove, H. Horlings et al., "Gene expression profiling and histopathological characterization of triplenegative/basal-like breast carcinomas," Breast Cancer Research, vol. 9, no. 5, article R65, 2007.

[163] S. M. A. Mahmoud, E. C. Paish, D. G. Powe et al., "Tumorinfiltrating $\mathrm{CD}^{+}$lymphocytes predict clinical outcome in breast cancer," Journal of Clinical Oncology, vol. 29, no. 15, pp. 1949-1955, 2011.

[164] L. Zhang, J. R. Conejo-Garcia, D. Katsaros et al., "Intratumoral $\mathrm{T}$ cells, recurrence, and survival in epithelial ovarian cancer," New England Journal of Medicine, vol. 348, no. 3, pp. 203-213, 2003.

[165] T. J. Curiel, G. Coukos, L. Zou et al., "Specific recruitment of regulatory $\mathrm{T}$ cells in ovarian carcinoma fosters immune privilege and predicts reduced survival," Nature Medicine, vol. 10, no. 9, pp. 942-949, 2004.

[166] W. Zou, "Immunosuppressive networks in the tumour environment and their therapeutic relevance," Nature Reviews Cancer, vol. 5, no. 4, pp. 263-274, 2005.

[167] R. C. Taylor, A. Patel, K. S. Panageas, K. J. Busam, and M. S. Brady, "Tumor-infiltrating lymphocytes predict sentinel lymph node positivity in patients with cutaneous melanoma," Journal of Clinical Oncology, vol. 25, no. 7, pp. 869-875, 2007.

[168] J.-Y. Shin, I.-H. Yoon, J.-S. Kim, B. Kim, and C.-G. Park, "Vascular endothelial growth factor-induced chemotaxis and IL-10 from T cells," Cellular Immunology, vol. 256, no. 1-2, pp. 72-78, 2009.

[169] A. Ruddell, P. Mezquita, K. A. Brandvold, A. Farr, and B. M. Iritani, "B lymphocyte-specific c-Myc expression stimulates early and functional expansion of the vasculature and lymphatics 
during lymphomagenesis," the American Journal of Pathology, vol. 163 , no. 6, pp. 2233-2245, 2003.

[170] A. Ruddell, M. I. Harrell, M. Furuya, S. B. Kirschbaum, and B. M. Iritani, "B lymphocytes promote lymphogenous metastasis of lymphoma and melanoma," Neoplasia, vol. 13, no. 8, pp. 748757, 2011.

[171] M. I. Harrell, B. M. Iritani, and A. Ruddell, "Tumor-induced sentinel lymph node lymphangiogenesis and increased lymph flow precede melanoma metastasis," The American Journal of Pathology, vol. 170, no. 2, pp. 774-786, 2007.

[172] D. B. Mendel, A. D. Laird, X. Xin et al., "In vivo antitumor activity of SU11248, a novel tyrosine kinase inhibitor targeting vascular endothelial growth factor and plateletderived growth factor receptors: determination of a pharmacokinetic/pharmacodynamic relationship," Clinical Cancer Research, vol. 9, no. 1 I, pp. 327-337, 2003.

[173] E. P. Rock, V. Goodman, J. X. Jiang et al., "Food and Drug Administration drug approval summary: sunitinib malate for the treatment of gastrointestinal stromal tumor and advanced renal cell carcinoma," Oncologist, vol. 12, no. 1, pp. 107-113, 2007.

[174] S. M. Wilhelm, C. Carter, L. Tang et al., "BAY 43-9006 exhibits broad spectrum oral antitumor activity and targets the RAF/MEK/ERK pathway and receptor tyrosine kinases involved in tumor progression and angiogenesis," Cancer Research, vol. 64, no. 19, pp. 7099-7109, 2004.

[175] R. C. Kane, A. T. Farrell, H. Saber et al., "Sorafenib for the treatment of advanced renal cell carcinoma," Clinical Cancer Research, vol. 12, no. 24, pp. 7271-7278, 2006.

[176] X.-W. He, X. Yu, T. Liu, S.-Y. Yu, and D.-J. Chen, "Vector-based RNA interference against vascular endothelial growth factor$\mathrm{C}$ inhibits tumor lymphangiogenesis and growth of colorectal cancer in vivo in mice," Chinese Medical Journal, vol. 121, no. 5, pp. 439-444, 2008.

[177] Z. Lui, Q. Ma, X. Wang, and Y. Zhang, "Inhibiting tumor growth of colorectal cancer by blocking the expression of vascular endothelial growth factor receptor 3 using interference vectorbased RNA interference," International Journal of Molecular Medicine, vol. 25, no. 1, pp. 59-64, 2010.

[178] R. V. Frolov and S. Singh, "Celecoxib and ion channels: a story of unexpected discoveries," European Journal of Pharmacology, vol. 730, pp. 61-71, 2014.

[179] L. Wang, W. Chen, X. Xie, Y. He, and X. Bai, "Celecoxib inhibits tumor growth and angiogenesis in an orthotopic implantation tumor model of human colon cancer," Experimental Oncology, vol. 30, no. 1, pp. 42-51, 2008.

[180] H. Liu, Y. Yang, J. Xiao et al., "Inhibition of cyclooxygenase2 suppresses lymph node metastasis via VEGF-C," Anatomical Record, vol. 292, no. 10, pp. 1577-1583, 2009.

[181] S. Takahashi, "Vascular Endothelial Growth Factor (VEGF), VEGF receptors and their inhibitors for antiangiogenic tumor therapy," Biological and Pharmaceutical Bulletin, vol. 34, no. 12, pp. 1785-1788, 2011.

[182] S. Yao and L. Chen, "Reviving exhausted T lymphocytes during chronic virus infection by B7-H1 blockade," Trends in Molecular Medicine, vol. 12, no. 6, pp. 244-246, 2006.

[183] S. Yao, Y. Zhu, and L. Chen, "Advances in targeting cell surface signalling molecules for immune modulation," Nature Reviews Drug Discovery, vol. 12, no. 2, pp. 130-146, 2013.

[184] D. S. Chen and I. Mellman, "Oncology meets immunology: the cancer-immunity cycle," Immunity, vol. 39, no. 1, pp. 1-10, 2013.
[185] O. Hamid and R. D. Carvajal, "Anti-programmed death-1 and anti-programmed death-ligand 1 antibodies in cancer therapy," Expert Opinion on Biological Therapy, vol. 13, no. 6, pp. 847-861, 2013.

[186] L. H. Butterfield, "Dendritic cells in cancer immunotherapy clinical trials: are we making progress?” Frontiers in Immunology, vol. 4, article 454, 2013.

[187] S. A. Grupp, M. Kalos, D. Barrett et al., "Chimeric antigen receptor-modified $\mathrm{T}$ cells for acute lymphoid leukemia," The New England Journal of Medicine, vol. 368, no. 16, pp. 1509-1518, 2013.

[188] R. J. Brentjens, I. Rivière, J. H. Park et al., "Safety and persistence of adoptively transferred autologous CD19-targeted T cells in patients with relapsed or chemotherapy refractory B-cell leukemias," Blood, vol. 118, no. 18, pp. 4817-4828, 2011.

[189] D. L. Porter, B. L. Levine, M. Kalos, A. Bagg, and C. H. June, "Chimeric antigen receptor-modified T cells in chronic lymphoid leukemia," New England Journal of Medicine, vol. 365, no. 8, pp. 725-733, 2011.

[190] O. S. Qureshi, Y. Zheng, K. Nakamura et al., "Trans-endocytosis of CD80 and CD86: a molecular basis for the cell-extrinsic function of CTLA-4," Science, vol. 332, no. 6029, pp. 600-603, 2011.

[191] G. Q. Phan, J. C. Yang, R. M. Sherry et al., "Cancer regression and autoimmunity induced by cytotoxic $\mathrm{T}$ lymphocyteassociated antigen 4 blockade in patients with metastatic melanoma," Proceedings of the National Academy of Sciences of the United States of America, vol. 100, no. 14, pp. 8372-8377, 2003.

[192] P. Waterhouse, J. M. Penninger, E. Timms et al., "Lymphoproliferative disorders with early lethality in mice deficient in Ctla-4," Science, vol. 270, no. 5238, pp. 985-988, 1995.

[193] U. Grohmann, C. Orabona, F. Fallarino et al., "CTLA-4-Ig regulates tryptophan catabolism in vivo," Nature Immunology, vol. 3, no. 11, pp. 1097-1101, 2002.

[194] M. Sasaki, H. Hasegawa, M. Kohno, A. Inoue, M. R. Ito, and S. Fujita, "Antagonist of secondary lymphoid-tissue chemokine (CCR ligand 21) prevents the development of chronic graftversus-host disease in mice," Journal of Immunology, vol. 170, no. 1, pp. 588-596, 2003.

[195] S. Schlereth, H. S. Lee, P. Khandelwal, and D. R. Saban, "Blocking CCR7 at the ocular surface impairs the pathogenic contribution of dendritic cells in allergic conjunctivitis," The American Journal of Pathology, vol. 180, no. 6, pp. 2351-2360, 2012.

[196] Y. Shuyi, D. Juping, Z. Zhiqun et al., "A critical role of CCR7 in invasiveness and metastasis of SW620 colon cancer cell in vitro and in vivo," Cancer Biology and Therapy, vol. 7, no. 7, pp. 10371043, 2008.

[197] F. E. Gonzalez, C. Ortiz, M. Reyes et al., "Melanoma cell lysate induces CCR7 expression and in vivo migration to draining lymph nodes of therapeutic human dendritic cells," Immunology, vol. 142, no. 3, pp. 369-405, 2014. 


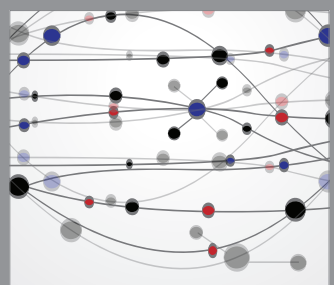

The Scientific World Journal
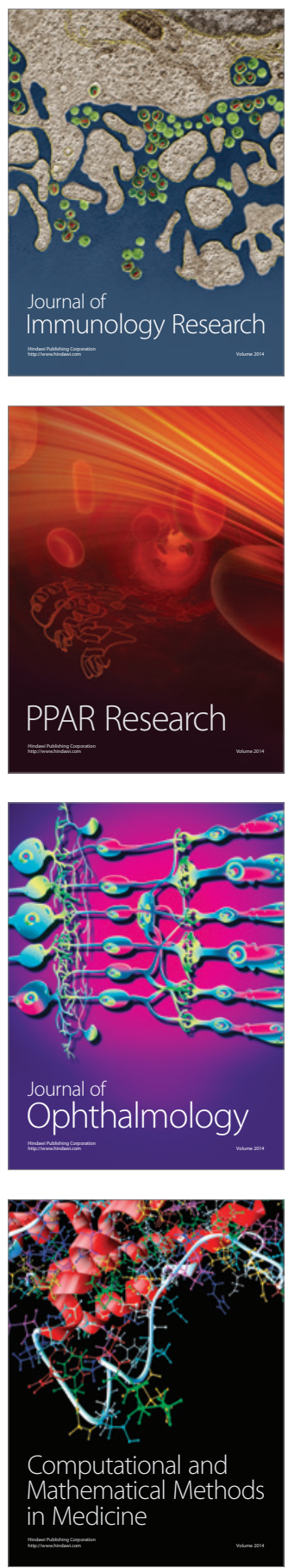

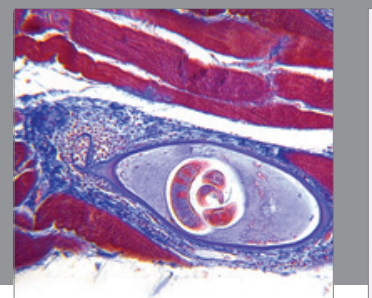

Gastroenterology

Research and Practice
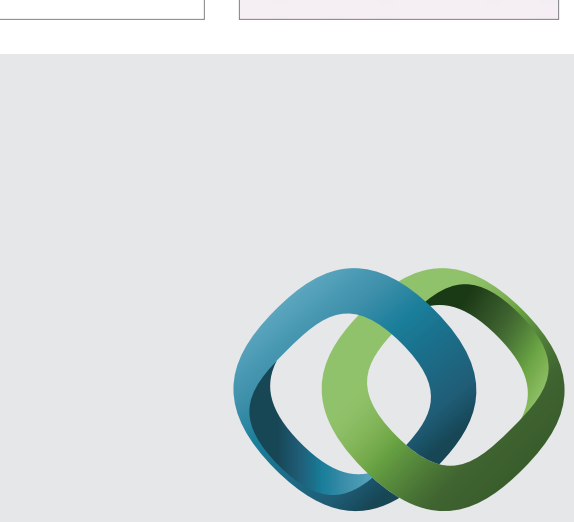

\section{Hindawi}

Submit your manuscripts at

http://www.hindawi.com
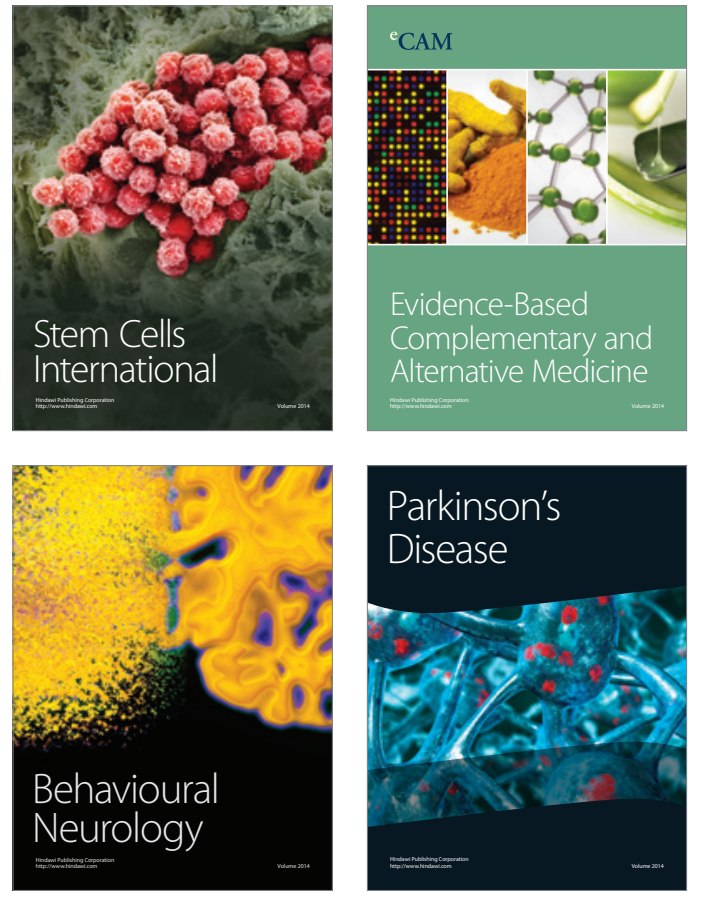
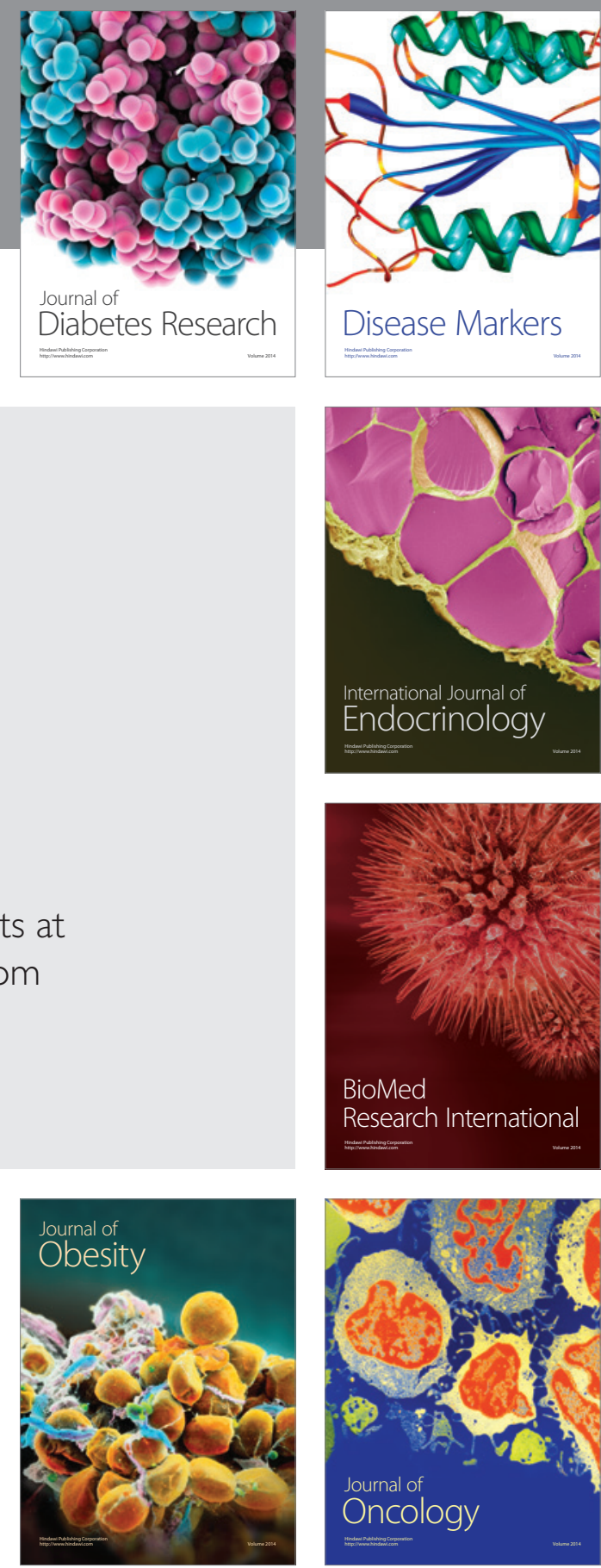

Disease Markers
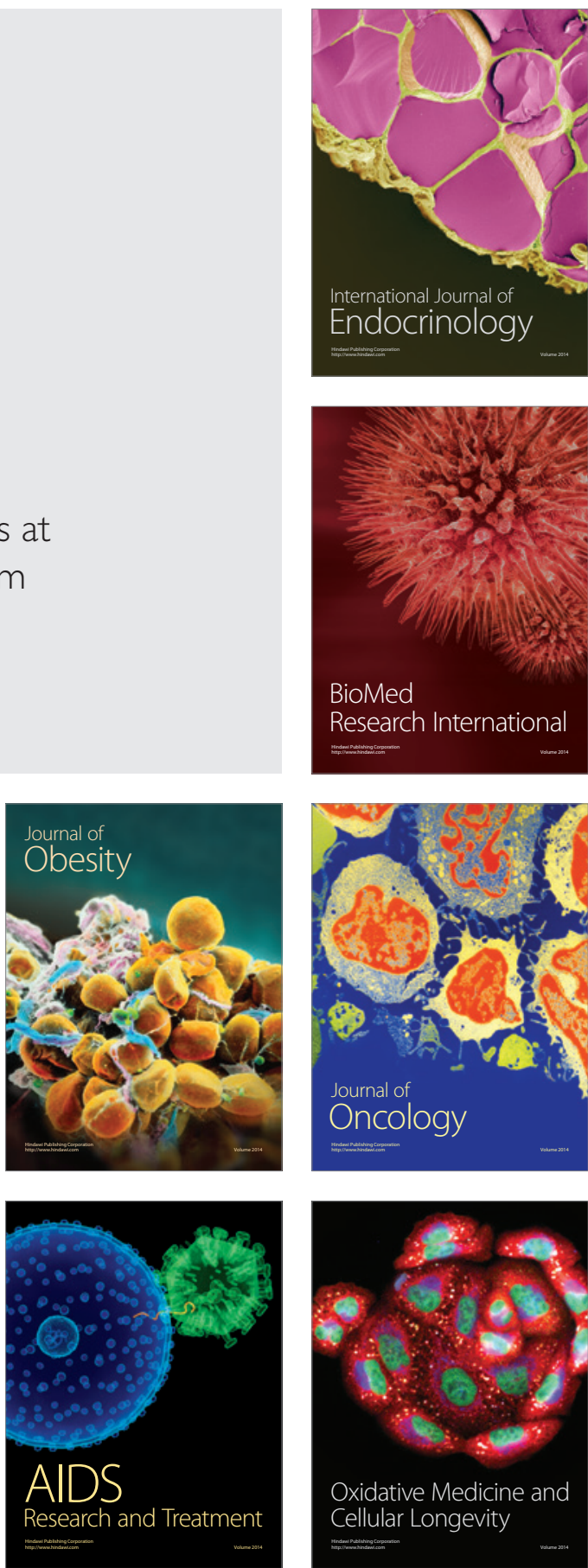